\title{
Hilltop Curvature Increases with the Square Root of Erosion Rate
}

E. J. Gabet ${ }^{1}$, S. M. Mudd ${ }^{2}$, R. W. Wood ${ }^{1}$, S. W. D. Grieve ${ }^{3}$, S. A. Binnie ${ }^{4}$, T. J. Dunai ${ }^{4}$

${ }^{1}$ Department of Geology, San Jose State University, San Jose, California, 95192, USA.

$6{ }^{2}$ School of Geosciences, University of Edinburgh, Edinburgh, UK, EH9 3FE.

$7 \quad{ }^{3}$ School of Geography, Queen Mary University of London, London, UK, E1 4NS.

$8{ }^{4}$ Institute for Geology and Mineralogy, University of Cologne, Germany, 50674.

Corresponding author: Emmanuel Gabet (manny.gabet@sjsu.edu)

\section{Key Points:}

- Hilltop curvature at our sites does not vary linearly with erosion rate, as predicted by theory

- The inferred transport coefficient appears to be insensitive to climate

- Processes affecting the underlying bedrock may control the shape of soil-mantled hillslopes

20 The shape of soil-mantled hillslopes is typically attributed to erosion rate and the transport

21 efficiency of the various processes that contribute to soil creep. While climate is generally

22 hypothesized to have an important influence on soil creep rates, a lack of uniformity in the

23 measurement of transport efficiency has been an obstacle to evaluating the controls on this

24 important landscape parameter. We addressed this problem by compiling a data set in which

25 the transport efficiency has been calculated using a single method, the analysis of hilltop

26 curvatures using 1-m LiDAR data, and the erosion rates have also been determined via a

27 single method, in-situ cosmogenic ${ }^{10} \mathrm{Be}$ concentrations. Moreover, to control for lithology,

28 we chose sites that are only underlain by resistant bedrock. The sites span a range of erosion

29 rates $(6-922 \mathrm{~mm} / \mathrm{kyr})$, mean annual precipitation $(39-320 \mathrm{~cm} / \mathrm{yr})$, and aridity index $(0.08-$

30 1.38). Surprisingly, we find that hilltop curvature varies with the square root of erosion rate, 
31 whereas previous studies predict a linear relationship. In addition, we find that the inferred

32 transport coefficient also varies with the square root of erosion rate but is insensitive to

33 climate. We explore various mechanisms that might link the transport coefficient to the

34 erosion rate and conclude that present theory regarding soil-mantled hillslopes is unable to

35 explain our results and is, therefore, incomplete. Finally, we tentatively suggest that

36 processes occurding in the bedrock (e.g., fracture generation) may play a role in the shape of

37 hillslope profiles at our sites.

38 Index Terms: 1826, 1819, 1862

\section{1. Introduction}

40 On soil-mantled surfaces too gentle for significant landsliding, particles are primarily

41 transported downslope by soil creep. Soil creep is a general term for the cumulative effect of

42 myriad individual processes that locally disturb soil, such as the freezing and thawing of pore

43 water [Anderson et al., 2013], shrink-swell cycles [Carson and Kirkby, 1972], dry ravel

44 [Anderson et al., 1959; Gabet, 2003], burrowing by animals [Gabet et al., 2003], and tree

45 throw [e.g., Denny and Goodlett, 1956]. Culling [1963] proposed that the rate of soil creep

$46\left(q_{\mathrm{s}} ; \mathrm{L}^{2} / \mathrm{T}\right)$ is linearly proportional to hillslope gradient, $S(\mathrm{~L} / \mathrm{L})$, such that

$47 \quad q_{s}=D S$

48 where $D\left(\mathrm{~L}^{2} / \mathrm{T}\right)$ is a sediment transport coefficient. The sediment transport coefficient, $D$, is a

49 measure of the efficiency of the various soil creep processes, and its magnitude sets the pace

50 for hillslope evolution [e.g., Fernandes and Dietrich, 1997; Roering et al., 1999]. Although a

51 nonlinear relationship between gradient and flux is supported by topographic analysis

52 [Andrews and Bucknam, 1987; Grieve et al., 2016; Hurst et al., 2012; Roering et al., 1999]

Gabet et al 
53 and physical simulations [Gabet, 2003; Roering et al., 2001b], this relationship reduces to

54 Eqn. (1) on slopes $<20^{\circ}$ [Hurst et al., 2012].

55 Our understanding of the controls on $D$ for a particular landscape is limited. Because

56 soil creep processes are typically climatically controlled, either directly (e.g., freeze-thaw) or

57 indirectly through climate's effect on the distribution of the biota, temperature and

58 precipitation are expected to have a dominant role in the transport efficiency of soil creep

59 [e.g., Dunne et al., 2010; Hanks, 2000; Pelletier et al., 2011]. Indeed, Hurst et al. [2013] and

60 Richardson et al. [2019] found that $D$ increases with mean annual precipitation, albeit

61 weakly; the latter also found that $D$ increases with the aridity index, which is the ratio

62 between precipitation and evapotranspiration [Trabucco and Zomer, 2019]. In contrast, Ben-

63 Asher et al. [2017] concluded that transport efficiency decreases with precipitation, although

64 this result was based on a small data set. Soil thickness [Furbish et al., 2009; Heimsath et al.,

65 2005] and soil texture [Furbish et al., 2009], as well as underlying lithology [Hurst et al.,

66 2013], may also be important factors. A lack of uniformity in measuring $D$, however, has

67 been an obstacle in investigating the effect of these various factors.

68 Determining the controls on the transport coefficient is important for a variety of

69 reasons. Because many landscapes are soil-mantled, not affected by overland flow, and too

70 gentle for significant landsliding, Eqn. (1) and its nonlinear counterpart are thought to offer a

71 complete description (or nearly so) of sediment transport across much of the Earth's surface.

72 Moreover, assuming steady-state topography, combining Eqn. (1) with a statement of mass

73 conservation yields

$74 \quad C_{H T}=-\frac{E}{D}\left(\frac{\rho_{s}}{\rho_{r}}\right)$ 
75 where $E$ is the erosion rate $(\mathrm{L} / \mathrm{T}), C_{H T}(1 / \mathrm{L})$ is the two-dimensional curvature (i.e., the

76 Laplacian of elevation) of a hill's ridgecrest, and $\rho_{\mathrm{s}}$ and $\rho_{\mathrm{r}}$ are the density $\left(\mathrm{L}^{3} / \mathrm{T}\right)$ of soil and

77 rock, respectively [Roering et al., 2007]. With this equation (and its nonlinear version), D

78 and $E$ are both assumed to be independent variables: $E$ is controlled by the rate at which the

79 lower boundary is lowered (e.g., via river incision in response to uplift), and $D$ is controlled

80 by the intensity of the various soil creep processes. According to this theory, the profile of a

81 hillslope adjusts itself such that its curvature satisfies Eqn. (2) [Culling, 1963; Gilbert, 1909].

82 Therefore, understanding the controls on the transport efficiency should provide insight into

83 hillslope form. In addition, studies have used Eqn. (1) and its nonlinear version to model the

84 degradation of fault scarps to estimate earthquake recurrence interval [e.g., Hanks and

85 Schwartz, 1987], and the results are sensitive to the value of the transport coefficient. Finally,

86 understanding the role of the various factors on $D$ is important as geologists attempt to infer

87 erosion rates based on topographic analyses [Hurst et al., 2012].

\section{2. Methods}

\subsection{Site selection and descriptions}

90 Appropriate sites were limited to watersheds which had both LiDAR and cosmogenic

$91{ }^{10} \mathrm{Be}$ data sets. The ${ }^{10} \mathrm{Be}$ data came from a global compilation [Harel et al., 2016], and the

92 associated LiDAR data were acquired from the OpenTopography (http://opentopo.sdsc.edu)

93 and USGS (https://viewer.nationalmap.gov) platforms. LiDAR data with spatial resolutions

94 coarser than 1-m cannot accurately resolve ridgeline curvatures in all settings [Grieve et al.,

95 2016] and so any sites without 1-m resolution data were excluded from the analysis. Because

96 ridgeline curvatures were used to estimate $D$ (see below), only watersheds that appeared to

97 be in topographic steady-state were chosen. For example, watersheds with clear knickpoints 
98 or with asymmetrical ridges were avoided, as well as steep watersheds advancing into low-

99 relief surfaces. Simulations of hillslope evolution suggest that hillslopes with declining

100 erosion rates adjust so quickly that they are difficult to differentiate from steady state

101 hillslopes; furthermore, hillslopes experiencing accelerated uplift only preserve the signature

102 of changing erosion rates for tens of thousands of years [Mudd, 2017]. Therefore, by

103 avoiding areas with obvious signs of landscape transience, we are less likely to find ridgeline

104 curvatures reflective of transient conditions. Thirty sites from six regions in the United States

105 met our criteria: the Olympic Peninsula (WA) [Belmont et al., 2007], the Feather River area

106 (CA) [Hurst et al., 2012; Riebe et al., 2001; Saucedo and Wagner, 1992], the San Gabriel

107 Mountains (CA) [DiBiase et al., 2010], Yucaipa Ridge (CA) [Binnie et al., 2007], the Idaho

108 Plateau (ID) [Wood, 2013], and the Blue Ridge Mountains (VA) [Duxbury, 2009] (Figure 1) .

109 Some of the regions (e.g., the San Gabriel Mountains) had ${ }^{10}$ Be data for sites not covered by

110 available LiDAR data and, thus, their full data-sets could not be used. Climatic data for these

111 sites were obtained from the 800-m resolution PRISM model [PRISM, 2014], which provides

112 recent (1981 - 2010) 30-yr means for annual precipitation (MAP) and annual temperature

113 (MAT) (Table 1). The aridity index for the sites was determined from Trabuco and Zomer

114 [2019]. While these data are for the modern climate, we assume that they are representative

115 (at least in a relative sense) of the climate state over the time-scale of the erosion rates

116 measured with ${ }^{10} \mathrm{Be}$ (i.e., $10^{3}-10^{5} \mathrm{yrs}$ ). To control for rock strength, we chose sites underlain

117 by lithologies known to be resistant to erosion: plutonic and metamorphic bedrock [e.g.,

118 Gabet, 2020; Hack, 1973] (Table 1). 
120 To ensure a consistent method for calculating erosion rates, they were determined

121 from ${ }^{10} \mathrm{Be}$ concentrations in detrital quartz grains (Table 1). For five of the study regions,

122 published ${ }^{10} \mathrm{Be}$ concentrations were used to calculate basin-scale erosion rates. For the Idaho

123 Plateau sites, ${ }^{10} \mathrm{Be}$ concentrations were measured from soil and fluvial sediment samples

124 collected for this study (see below). For all six study regions, erosion rates were calculated

125 from the ${ }^{10} \mathrm{Be}$ concentrations using a single algorithm [Mudd et al., 2016].

126 A full description of the Idaho Plateau field area can be found in Wood [2013].

127 Ridgetop and basin-scale denudation rates were determined by measuring cosmogenic ${ }^{10} \mathrm{Be}$

128 concentrations in quartz [Brown et al., 1995; Granger et al., 1996]. The ridgetop rates were

129 determined from soil samples taken from the top $20 \mathrm{~cm}$ of the regolith at three sites. For the

130 basin-scale erosion rates, fluvial sediment was taken from three $1^{\text {st }}$-order streams. Pure quartz

131 fractions from the crushed and sieved $(250-710 \mu \mathrm{m})$ and magnetically separated samples

132 were obtained using published procedures [Kohl and Nishiizumi, 1992; Mifsud et al., 2013].

133 ICP-OES analysis of purity was undertaken on splits of the etched quartz. Samples were

134 spiked with $200 \mu \mathrm{g}$ of a commercial Be carrier (Scharlab Berylium ICP standard solution)

135 and prepared as AMS targets at the University of Cologne using a standard sample

136 preparation method [2015]. The samples were prepared alongside a reagent blank; ${ }^{10} \mathrm{Be}$

137 concentrations following blank subtraction are reported in Table 2. Blank corrections are $<2$

$138 \%$, except for sample S2, for which the correction is $<5 \%$. Samples were measured on

139 CologneAMS [Dewald et al., 2013] and normalized to reference standards [2007].

140 Uncertainties in the concentrations are estimated by propagating the uncertainties of the 
141 AMS measurements and mass of Be added during spiking (estimated $1 \sigma$ uncertainty of 1\%)

142 of both the samples and the blank.

$143{ }^{10} \mathrm{Be}$ concentrations were converted to denudation rates with the CAIRN software

144 package, which accounts for topographic shielding and snow shielding [Mudd et al., 2016].

145 We calculated snow shielding by first fitting a bilinear trend in snow water equivalent (SWE)

146 as a function of elevation based on regional climate data from the National Oceanic and

147 Atmospheric Association [NOAA, 2016] and following Kirchner et al. [2014]. SWE averages

148 were converted to snow shielding values by assuming that snow reduces production solely by

149 spallation [Mudd et al., 2016]. Snow shielding is highly uncertain because of the difficulty of

150 estimating the average SWE over the timescales of $10^{3}-10^{4}$ years. We calculated

151 denudation rates with no snow shielding to assess the sensitivity of denudation rate to snow

152 thickness and found that, without accounting for snow, denudation rate estimates could be as

153 much as $15 \%$ higher (for sample S3) but, for most samples, the differences were less than

$15410 \%$. Uncertainties from analytical error and from uncertainties in production scaling and

155 shielding are presented in Table 1 [Mudd et al., 2016].

\subsection{Transport Coefficient Calculations}

157 Direct estimates of the transport efficiency by field measurements of sediment fluxes

158 over the relevant time and spatial scales across a range of landscapes are impractical. Instead,

159 along ridgelines, where slopes are gentle and soil creep is well described by Eqn. (1), the

160 transport coefficient can be calculated by rewriting Eqn. (2) as

161

$$
D=-\left(\frac{E}{C_{H T}}\right)\left(\frac{\rho_{r}}{\rho_{s}}\right)
$$


162 The ratio $\rho_{\mathrm{r}} / \rho_{\mathrm{s}}$ was assumed to be 2 [Hurst et al., 2012]; this value is probably only

163 approximately correct for each of our sites and likely varies by $\pm 25 \%$. Ridgeline curvatures

164 were calculated from a 1-m LiDAR DEM for each site using a six-term polynomial function

165 to fit the elevation data within a circular sliding window with a diameter of $14 \mathrm{~m}$. A value of

$16614 \mathrm{~m}$ for the analysis window was chosen based on sensitivity analyses presented in Grieve

167 et al. [2016] which followed the method for identifying the optimal window diameter

168 described in Roering et al. [2010] and Hurst et al. [2012].

169 The second derivative of the polynomial function at the window's center is that cell's

170 two-dimensional curvature. Because topographic noise could produce outliers, the median of

171 the curvatures along each watershed's ridgeline was used in our analyses [Hurst et al., 2012].

172 The average slopes $( \pm 1 \sigma)$ along the ridgelines, determined as the first derivative of the

173 polynomial function, ranged from $0.5 \pm 3^{\circ}$ (Blue Ridge Mtns) to $9 \pm 6^{\circ}$ (Yucaipa Ridge),

174 thereby validating the use of Eqn. (1). Note that, even at the steepest site along Yucaipa

175 Ridge, nearly $95 \%$ of the area analyzed had slopes $<20^{\circ}$. Finally, an automated procedure

176 was used to detect the presence of bedrock outcrops along the ridgelines [Milodowski et al.,

$1772015]$ to confirm that the sites were mantled with soil. One Yucaipa Ridge site had 75\% soil-

178 cover and the other had $90 \%$ soil-cover; the soil-cover at the other sites ranged from 97 to

$179100 \%$. Observations of Google Earth ${ }^{\mathrm{TM}}$ imagery supported these estimates.

\subsection{Additional Data}

The dataset described above was supplemented with data selected from a compilation

182 presented in Richardson et al. [2019] (Table 1). From this compilation, four sites met our

183 criteria: the ridgelines were symmetrical, transport coefficients were estimated by analyzing

184 ridgetop curvatures from 1-m LiDAR data, erosion rates were determined with cosmogenic 
$185{ }^{10} \mathrm{Be}$, and the soils were derived from resistant lithologies (Table 1). The only difference is

186 that Richardson et al. used a 15-m window for their curvature analysis whereas our study

187 used a 14-m window; we consider this difference to be insignificant. With the combined

188 datasets, the sites represent a range of erosion rates from 6 to $922 \mathrm{~mm} / \mathrm{kyr}$, a range of mean

189 annual precipitation from 39 to $320 \mathrm{~cm} / \mathrm{yr}$, a range of mean annual temperature from 2 to $15^{\circ}$

$190 \mathrm{C}$, and range of aridity index from 0.08 to 1.38 (Table 1 ).

\subsection{Correcting for Grid Resolution}

As erosion rates increase, ridgelines become sharper, which could potentially weaken

193 the ability to accurately measure curvature given a fixed grid resolution. In particular, this

194 grid-resolution effect could lead to an increasing underestimate of curvature as ridgelines

195 sharpen with increasing erosion rates, thereby artificially introducing a positive relationship

196 between $D$ and $E$. To correct for this potential artefact, we performed an analysis in which we

197 compared the estimates of the transport efficiency with those from idealized one-dimensional

198 (1D) hillslopes. We assumed our ridges can be approximated as one-dimensional because

199 curvature perpendicular to ridgelines far exceeds curvature parallel to our ridgelines.

200 To begin, we solved for the elevation of an idealized 1D hillslope by assuming that a

201 nonlinear sediment flux law describes sediment transport on our hillslopes [e.g., Andrews

202 and Bucknam, 1987; Roering et al., 1999]

203

$$
q_{s}=-\frac{D \frac{\partial z}{\partial x}}{1-\left(\left|\frac{\partial z}{\partial x}\right| / S_{c}\right)^{2}}
$$

204 where $q_{s}$ is sediment flux $\left(\mathrm{m}^{2} / \mathrm{yr}\right), D$ is the sediment transport coefficient $\left(\mathrm{m}^{2} / \mathrm{yr}\right), z$ is the 205 surface elevation, $x$ is a horizontal distance, and $S_{c}$ is a critical slope angle. As noted earlier, 
206 this equation reduces to Eqn. (1) at gentle slopes. Inserting Eqn. (4) into a statement of mass

207 conservation and solving it under steady-state conditions yields an expression for the

208 elevation of a hillslope [Roering et al., 2001a]:

209

$$
z=-\frac{S_{c}^{2}}{2 \beta}\left[\sqrt{D^{2}+\left(\frac{2 \beta x}{S_{c}^{2}}\right)}-D \ln \left(\frac{S_{2}}{2 \beta} \sqrt{D^{2}+\left(\frac{2 \beta x}{S_{c}^{2}}\right)^{2}}+\frac{S_{c} D}{2 \beta}\right)\right]+c
$$

210 where $\beta$ is the ratio between rock and soil density multiplied by the erosion rate $\left(\left(\rho_{\mathrm{r}} / \rho_{\mathrm{s}}\right)^{*} E\right)$

211 and $c$ is a constant that sets the absolute elevation of the hillslope profile. At the divide $(x=0$

$212 \mathrm{~m})$, the curvature is equal to:

$$
\left(\frac{d^{2} z}{d x^{2}}\right)_{H T}=-\frac{\beta}{D}
$$

As described earlier, curvature at each site was measured from gridded 1-m

215 topographic data. To mimic this procedure on the synthetic hillslope, we solved Eqn. (5) on a

216 grid of points with a spacing of $1 \mathrm{~m}$. Random noise was then imposed on each gridded data

217 point from a uniform distribution ranging from -0.1 to $0.1 \mathrm{~m}$, which is a conservative

218 estimate of vertical error in typical airborne LiDAR data. As with the real landscapes, a $2^{\text {nd }}-$

219 order polynomial equation was fitted across the ridgetop over a 14-m window and the

220 curvature was calculated at the center node.

221 However, in any gridded topography, the highest true elevation of the ridge may not

222 be located exactly on the grid sampling point. The exact location of the ridge may be offset

223 from the highest gridded pixel by up to half a pixel width. In Eqn. (5), the ridge is located at

$224 x=0$ meters, but to account for the possibility that the ridgeline does not correspond to the

225 highest pixel, we allowed the gridded points to shift laterally by $0.5 \mathrm{~m}$ to produce an offset

226 between the center point in the gridded data and the ridgeline. 
For each study site (Table 1), the values of $\beta$ and $S_{c}$ were calculated using the erosion

228 rate and measured curvature to produce idealized ridgetop profiles. Random noise was then

229 applied to the profile, the grid was shifted, and the 'synthetic' curvature was calculated from

230 the fitted $2^{\text {nd }}$-order polynomial. This process was repeated with variations in $D$ until the

231 synthetic curvature matched the curvature measured from the topographic data. We

232 performed 250 iterations of adding random noise to a profile centered on the hilltop, and 250

233 iterations of random noise to a profile centered $0.5 \mathrm{~m}$ from the hilltop. These calculations

234 resulted in 500 values for the sediment transport coefficient that account for (1) sampling a

235 continuous hillslope with gridded data, (2) random noise from the DEM, and (3) a potential

236 mismatch between the actual location of the hillcrest and the highest pixel along the 1D ridge

237 in the DEM.

238

239 3. Results

240 We find that the 'raw' hilltop curvature (i.e., uncorrected for grid-scale effects) is

241 strongly correlated with the approximate square root of erosion rate: $C_{H T} \propto E^{0.48}$ (Figure 2).

242 The 'corrected' hilltop curvature is also correlated with erosion rate although the exponent in

243 the regression increases to 0.53 (Figure 3). In addition, the transport coefficient (calculated

244 from the corrected hilltop curvatures) varies with erosion rate, whereby $D \propto E^{0.47}$ (Figure 4).

245 The transport efficiency is not correlated with any of the climate parameters (Figure

246 5) nor with the 'effective energy and mass transfer' variable (plot not shown), a parameter

247 which incorporates both MAT and MAP to represent the influence of climate on soil

248 processes [Rasmussen and Tabor, 2007]. 


\section{Discussion}

250 Our results indicate that, at the sites we examined, erosion rate appears to have a

251 dominant control on the efficiency of sediment transport. The apparent role of erosion rate on

252 the efficiency of hillslope sediment transport and the insignificance of climate is unexpected

253 considering that others have found a climatic influence on the value of D [Hurst et al., 2013;

254 Richardson et al., 2019]. In contrast to our results, Richardson et al. [2019] compiled erosion

255 rate and transport coefficient data from studies which used a variety of techniques to estimate

256 these values, and their data included sites in a range of lithologies as well as from regions

257 with a greater range in precipitation. As a result, their larger data set may be better suited for

258 detecting an underlying climatic influence.

259 To explore how transport efficiency might increase with erosion rate, the factors

260 contributing to soil creep can be assessed with two approaches. For discrete, intermittent

261 large-scale soil creep events (e.g., tree throw), the transport efficiency can be calculated as

$$
D=f_{e} \bar{V} \bar{d}
$$

265 where $f_{\mathrm{e}}$ is the frequency of events per unit area $\left(\mathrm{T}^{-1} \mathrm{~L}^{-2}\right), \bar{V}$ is the average volume $\left(\mathrm{L}^{3}\right)$ of soil

266 displaced with each event, and $\bar{d}$ is the average distance (L) that volume of soil is displaced

267 [Gabet, 2000]. For example, in the case of tree throw, the transport coefficient will depend

268 on the number of toppled trees over a period of time, the average volume of soil in the root

269 plates, and the distance that the root plates are displaced [Gabet et al., 2003]. We are not

270 aware of any reason why any of these three factors would increase with erosion rate. Indeed,

271 in the case of bioturbation, $\bar{V}$ and $f_{\mathrm{e}}$ might be expected to decrease. For example, because 
272 soils tend to be thinner where erosion rates are high [e.g., Gabet et al., 2015], the volume of

273 soil available for transport by three throw should decrease. In addition, the frequency of

274 bioturbation might be expected to decrease in rapidly eroding landscapes because of lower

275 plant biomass [Milodowski et al., 2014].

276 For dilational creep processes in which soil particles are lofted up and then settle

277 down due to gravity, $D$ can be expressed as [Furbish et al., 2009]

278

279

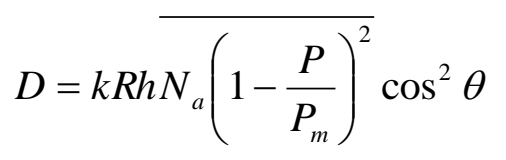

281 where $k$ is an empirically determined dimensionless constant that accounts for particle shape

282 and the relationship between mean free path length and the vertical displacement of particles,

$283 R$ is particle radius $(\mathrm{L}), h$ is soil thickness $(\mathrm{L}), P$ is particle concentration $\left(\mathrm{L}^{3} \mathrm{~L}^{-3}\right), P_{\mathrm{m}}$ is the

284 maximum value of $P, N_{\mathrm{a}}$ is the particle activation rate $\left(\mathrm{T}^{-1}\right), \theta$ is the hillslope angle $\left(^{\circ}\right.$ ) (equal

285 to zero at the ridgecrest), and the overbar signifies vertically averaged quantities. The particle

286 concentration (a function of soil bulk density) is not likely to be dependent on erosion rate to

287 a significant degree and, if it is, the term in parentheses would likely decrease with increasing

288 erosion rate, thereby suppressing the value of $D$. Because soils are thinner in rapidly eroding

289 landscapes [e.g., Gabet et al., 2015], variations in soil thickness also cannot account for the

290 increase in transport efficiency with erosion rate; indeed, the inverse relationship between

291 soil thickness and erosion rate should lead to an inverse relationship between $D$ and $E$, the

292 opposite of what we have found. With respect to particle activation rate, we are not aware of

293 any studies that have correlated this variable with erosion rate; however, because rapidly 
294 eroding hillslopes tend to have thinner and more exposed soils [e.g., Gabet et al., 2015], the

295 particle activation rate in these landscapes could potentially be higher, which could lead to an

296 increase in $D$ with $E$. For example, a decrease in vegetation biomass with increasing erosion

297 rate [Milodowski et al., 2014] could leave the soil surface more vulnerable to raindrop impact

298 [Dunne et al., 2010]. Nevertheless, as noted above, a reduction in biomass might also be

299 expected to damp bioturbation, thereby reducing the transport efficiency.

300 The final variable from Eqn. (8) to be explored is particle diameter, $R$. Previous

301 studies have documented an increase in particle diameter with erosion rate [Attal et al., 2015;

302 Riebe et al., 2015]. Where erosion is slow, particles are exposed to weathering processes for

303 longer periods of time because of longer soil residence times and, as a result, particles

304 become smaller [e.g., Mudd and Yoo, 2010]. In Eqn. (8), particle size is a factor in the

305 transport coefficient because it controls the mean free path of particles in a soil creeping by

306 dilational processes [Furbish et al., 2009]. Although field data from Neeley et al. [2019]

307 suggest that coarser soils have a higher transport coefficient, laboratory experiments have

308 demonstrated that, for the same input of energy, coarse-grained soils will creep faster than

309 fine-grained soils [Supplement to Deshpande et al., 2020]. In addition, of the various factors

310 that could affect the rate of soil creep, particle size is the one with the most potential to vary

311 by multiple orders-of-magnitude between watersheds eroding at different rates [Marshall and

312 Sklar, 2012]. For example, while the data are limited, particle radius along a ridgeline

313 increases with erosion rate at the Feather River site (Figure 6).

314 While particle size is a potential candidate for explaining the relationship between

315 transport efficiency and erosion rate found here, this hypothesis raises some perplexing

316 issues. First, whereas the relationship between particle size and erosion rate is likely to be 
317 constant within a single region, one would expect them to vary between regions according to

318 climate and lithology (although we tried to control for rock strength, variations in texture, for

319 example, could affect particle size). However, despite the expected regional variations in

320 these factors, the sites fall along the same $D$ vs. $E$ trendline (Figure 3 ). Second, because the

321 more rapid weathering rates in wetter climates should lead to smaller soil particles [Marshall

322 and Sklar, 2012], the transport coefficient should decrease in wetter climates. However, we

323 find no relationship between mean annual precipitation and $D$ (Figure 5).

324 Another potential explanation may be that the transport efficiency is sensitive to slope.

325 Landscapes that are eroding quickly are generally steeper than those that are eroding more

326 slowly. For example, the slopes at the ridgecrests $\left(S_{\mathrm{HT}}\right)$ at our sites increase with the

327 approximate square root of erosion rate (Figure 7). Some property of the soil (e.g., its

328 resistance to disturbance) may be affected by the gradient such that its transport efficiency

329 increases on steeper slopes (P. Richardson, pers. comm.). Furbish and Haff [2010] suggest

330 that the rate at which soil is mobilized might also increase with slope. To explore the

331 consequences of a slope-dependent transport coefficient, we define a new variable, $D_{\mathrm{s}}\left(\mathrm{L}^{2} / \mathrm{T}\right)$

$332 \quad D_{s}=K S$

333 such that

334

$$
q_{s}=D_{s} S
$$

335 or

$336 \quad q_{s}=K S^{2}$

337 where $K\left(\mathrm{~L}^{2} / \mathrm{T}\right)$ is a constant with the same properties as $D$. Inserting Eqn. (11b) into a

338 statement of mass conservation 


$$
\rho_{r} \frac{d z}{d t}=-\rho_{s} \frac{d q_{s}}{d x}
$$

340 and integrating twice assuming steady state $(\mathrm{d} z / \mathrm{d} t=E)$ and $\rho_{\mathrm{r}} / \rho_{\mathrm{s}}=2$ yields

$341 \quad E=K C S / 2$

342 To specify that this relationship is applied to the hilltops, we rewrite it as

$343 \quad E=K C_{H T} S_{H T} / 2$

344 Thus, the assumption that the transport coefficient increases linearly with slope implies a

345 linear relationship between the erosion rate and the product of curvature and slope. Indeed, a

346 power-law regression between the two yields an exponent of unity, offering support for the

347 hypothesis that the transport coefficient is slope-dependent (Figure 8). However, because

348 slope and curvature are linearly related along a parabolic curve, Eqn. (13b) is functionally

349 equivalent to $E \propto C^{2}$ or $C \propto E^{1 / 2}$, which is the original relationship presented in Figure 3 . In

350 other words, the linear relationship between $E$ and $C_{\mathrm{HT}} \mathrm{S}_{\mathrm{HT}}$ may simply be a mathematical

351 artefact, and the sediment flux relationship represented by Eqn. (11b) would need to be

352 validated independently. Finally, note that Eqn. (11b) is quite different from the nonlinear

353 sediment flux equation proposed elsewhere [Andrews and Bucknam, 1987; Gabet, 2003;

354 Roering et al., 1999], particularly at lower slopes (Figure 9).

355 The lack of a clear and robust mechanistic link between $D$ and $E$, as well as the square

356 root dependency of the hilltop curvature on erosion rate when Eqn. (2) predicts a linear

357 relationship, suggests that the present theory explaining the profile of soil-mantled hillslopes

358 is incomplete. We tentatively propose that, in resistant lithologies, hillslope curvature may be

359 partially, if not mostly, controlled by processes occuring within the bedrock, rather than the

360 soil. Indeed, in an eroding landscape, the soil on a hill is just a thin mantle covering a much

361 larger bedrock mass; the shape of the hill, therefore, should reflect the shape of the 
362 underlying bedrock and the processes acting within it [e.g., Rempe and Dietrich, 2014].

363 However, the absence of any climatic influence in our results suggests that these bedrock

364 processes are not associated with the typical chemical and physical weathering processes;

365 instead, they are likely related to a more universal mechanism. Recent work has begun

366 investigating how, even in soil-mantled landscapes, the generation of fractures in bedrock by

367 topographic stresses may exert an important influence on landform shape [e.g., Clair et al.,

368 2015; Pelletier, 2017; Slim et al., 2015]. However, whereas the regional tectonic stress is an

369 important contributor to topographic stresses [e.g.,Clair et al., 2015; Miller and Dunne,

370 1996], the tectonic stress regime varies widely between our sites. For example, the regional

371 stresses are compressional in the San Gabriel Mountains but extensional in the Wasatch

372 Mountains and the Feather River study area [Heidbach et al., 2016; Wakabayashi and

373 Sawyer, 2000]. Therefore, the alignment of these sites along the same trendline (Figure 2)

374 suggests that our present understanding of rock fracture by topographic stresses is unable to

375 explain our results.

376 One potential avenue for further investigations may be an examination of the time-

377 dependent nature of fracture growth. At high erosion rates, near-surface bedrock is

378 rejuvenated more quickly, thereby limiting the fracture density. In contrast, in environments

379 where the erosion rate is slower and the rejuvenation of the surface occurs less frequently, the

380 near-surface bedrock may have a higher fracture density as it accumulates damage over time.

381 The relationship found here between hilltop curvature and erosion rate, therefore, may be

382 related to the strength of the underlying rock mass in a way that is not yet understood. As a

383 preliminary test of this idea, we analyzed the data from four sites that met our criteria but

384 were underlain by presumably weak lithologies, sedimentary bedrock or highly sheared 
385 metamorphic bedrock [Perron et al., 2012; Richardson et al., 2019]. A comparison of the

386 hilltop curvatures between our original data-set consisting of resistant rocks and the data

387 from the weaker lithologies suggests that, for the same erosion rate, the weaker bedrock

388 forms hilltops with lower curvatures (Figure 10). While the data set from presumably weak

389 lithologies is limited, it supports our hypothesis that weaker bedrock is associated with lower

390 curvatures. Although one might argue that the lower curvatures seen in hillslopes underlain

391 by weaker lithologies could be a result of higher transport efficiencies, a clear mechanistic

392 link between bedrock strength and transport efficiency is lacking (see below), especially

393 considering that most soil creep processes (e.g., tree throw) do not appear to be limited by

394 soil texture.

395 If bedrock processes have an important influence on hillslope form, then hilltop

396 curvature cannot be used for estimating the transport coefficient, at least in landscapes

397 underlain by resistant rock. This limitation might explain why we were unable to detect any

398 climatic influence on $D$, in contrast to compilations that include estimates of $D$ from a variety

399 of techniques [Hurst et al., 2013; Richardson et al., 2019]. In addition, if hillslope form is

400 primarily dependent on the underlying bedrock, estimates of $D$ based on topographic

401 characteristics might be expected to be of different magnitudes than estimates from other

402 techniques. Indeed, in the compilation presented by Richardson et al. [2019], transport

403 coefficients estimated from relief and hilltop curvature are generally 5 - 10 times higher than

404 those estimated from the modeling of scarps for the same aridity index (a factor that was

405 determined to be a control on $D$ ) despite the fact that estimates based on scarp evolution were

406 often performed on slopes comprised of unconsolidated sediment, which might be expected

407 to have higher values of $D$. Therefore, the mismatch between the estimates of the transport 
408 coefficient based on topographic metrics and those based on other techniques suggests that

409 some other factor is influencing hillslope shape.

\section{5. Conclusions}

411 The square-root dependency of hilltop curvature on erosion rate challenges the

412 prevailing theory linking soil creep to the shape of soil-mantled hillslopes, which predicts a

413 linear relationship between the two. This dependency could be explained if the transport

414 coefficient also varies with the square root of erosion rate. However, we are unable to

415 propose a robust mechanism linking the transport coefficient to the erosion rate. Given the

416 difficulties in accounting for our results within the standard theory of hillslope evolution, we

417 tentatively propose that in landscapes underlain by resistant lithologies, hillslope curvature is

418 not related to soil creep but is, instead, controlled by processes in the underlying bedrock.

419 Finally, the robust relationship between ridgetop curvature and erosion rate across a

420 range of climatic conditions suggests that the latter can be estimated directly from

421 topographic analysis in rock types similar to those analyzed in this study. However, erosion

422 rates determined with this procedure must incorporate uncertainties in the original ${ }^{10} \mathrm{Be}$

423 erosion rate measurements, uncertainties in the curvature measurements, and the uncertainty

424 in the regression between $C_{\mathrm{HT}}$ and $E$. Nevertheless, our results have the potential for

425 providing a simple approach for estimating watershed-scale erosion rates through the

426 measurement of hilltop curvatures.

\section{Acknowledgments}

429 Idaho field work for this project was conducted with assistance from B. Wood, S.

430 Powell, and E. Hewitt. There were no real or perceived financial conflicts of interest for any 
431 author nor did any author have an affiliation that could be perceived as having a conflict of

432 interest with respect to the results of this paper. The data supporting the conclusions can be

433 found in the tables and references. This project was partially funded by graduate student

434 research grants from GSA and SJSU. LiDAR elevation data were acquired with a Seed

435 Project from the National Center for Airborne Laser Mapping in the summer of 2011.

436 Software used for analysis was developed under NERC grant NE/J009970/1. We are grateful

437 to J. Pelletier, J. Roering, and P. Richardson for their careful reviews and helpful comments,

438 and D. Furbish for extended and insightful discussions.

440 Data Availability Statement

441 Original data for this research are provided in Tables 1 and 2. Additional data were

442 compiled from Belmont et al. [2007], Binnie et al. [2007], Dibiase et al. [2010], Duxbury

443 [2009], Hurst et al. [2012], Richardson et al. [2019], and Riebe et al. [2001].

\section{References}

445 Anderson, H. W., G. B. Coleman, and P. J. Zinke (1959), Summer slides and winter scour, dry-wet erosion in Southern California mountains: U.S.D.A., Forest Service, Pacific Southwest Forest and Range Experiment Station Technical Paper PSW-36.

Anderson, R. S., S. P. Anderson, and G. E. Tucker (2013), Rock damage and regolith transport by frost: An example of climate modulation of the geomorphology of the critical zone, Earth Surface Processes and Landforms, 38(3), 299-316.

Andrews, D. J., and R. C. Bucknam (1987), Fitting degradation of shoreline scarps by a nonlinear diffusion model, Journal of Geophysical Research, 92(B12), 12,857$812,867$.

Attal, M., S. M. Mudd, M. D. Hurst, B. Weinman, K. Yoo, and M. Naylor (2015), Impact of change in erosion rate and landscape steepness on hillslope and fluvial sediments grain size in the Feather River Basin (Sierra Nevada, California), Earth Surface Dynamics, 2, 1047-1092.

Belmont, P., F. J. Pazzaglia, and J. C. Gosse (2007), Cosmogenic 10Be as a tracer for hillslope and channel sediment dynamics in the Clearwater River, western Washington State, Earth and Planetary Science Letters, 264, 123-135. 
Ben-Asher, M., I. Haviv, J. J. Roering, and O. Crouvi (2017), The influence of climate and microclimate (aspect) on soil creep efficiency: Cinder cone morphology and evolution along the eastern Mediterranean Golan Heights, Earth Surface Processes and Landforms, 42(15), 2649-2662.

Binnie, S. A., W. M. Phillips, M. A. Summerfield, and K. Fifield (2007), Tectonic uplift, threshold hillslopes, and denudation rates in a developing mountain range, Geology, 35, 743-746.

Binnie, S. A., T. J. Dunai, E. Voronina, T. Goral, S. Heinze, and A. Dewald (2015), Separation of Be and Al for AMS using single-step column chromatography, Nuclear Instruments and Methods in Physics Research Section B: Beam Interactions with Materials and Atoms, 361, 397-401.

Brown, E. T., R. F. Stallard, M. C. Larsen, G. M. Raisbeck, and F. Yiou (1995), Denudation rates determined from the accumulation of in situ-produced $10 \mathrm{Be}$ in the Luquillo Experimental Forest, Puerto Rico, Earth and Planetary Science Letters, 129(1-4), 193-202.

Carson, M. A., and M. J. Kirkby (1972), Hillslope form and process, 475 pp., Cambridge University Press, New York.

Clair, J. S., S. Moon, W. S. Holbrook, J. T. Perron, C. S. Riebe, S. J. Martel, B. Carr, C. Harman, K. Singha, and D. d. Richter (2015), Geophysical imaging reveals topographic stress control of bedrock weathering, Science, 350, 534-538.

Culling, W. E. H. (1963), Soil creep and the development of hillside slopes, Journal of Geology, 71, 127-161.

Denny, C., and J. Goodlett (1956), Microrelief resulting from fallen trees, USGS Professional Publication, 288, 59-68.

Deshpande, N., D. J. Furbish, P. Arratia, and D. Jerolmack (2020), The perpetual fragility of creeping hillslopes, EarthArXiv, doi:10.31223/osf.io/qc9jh.

Dewald, A., et al. (2013), CologneAMS, a dedicated center for accelerator mass spectrometry in Germany, Nuclear Instruments and Methods in Physics Research Section B: Beam Interactions with Materials and Atoms, 294, 18-23.

DiBiase, R. A., K. X. Whipple, A. M. Heimsath, and W. B. Ouimet (2010), Landscape form and millenial erosion rates in the San Gabriel Mountains, CA, Earth and Planetary Science Letters, 289, 134-144.

Dunne, T., D. V. Malmon, and S. M. Mudd (2010), A rain splash transport equation assimilating field and laboratory measurements, Journal of Geophysical Research Earth Surface, 115(F01001), 1-16.

Duxbury, J. (2009), Erosion rates in and around the Shenandoah National Park, VA, determined using analysis of cosmogenic 10Be, MS thesis, $123 \mathrm{pp}$, University of Vermont.

Fernandes, N. F., and W. E. Dietrich (1997), Hillslope evolution by diffusive processes: the timescale for equilibrium adjustments, Water Resources Research, 33(6), 1307-1318.

Furbish, D. J., and P. K. Haff (2010), From divots to swales: Hillslope sediment transport across divers length scales, Journal of Geophysical Research, 115(F03001), doi:10.1029/2009JF001576.

Furbish, D. J., P. K. Haff, W. E. Dietrich, and A. M. Heimsath (2009), Statistical description of slope-dependent soil transport and the diffusion-like coefficient, Journal of Geophysical Research, 114(F00A05), doi:10.1029/2009JF001267. 
Gabet, E. J. (2000), Gopher bioturbation: Field evidence for nonlinear hillslope diffusion, Earth Surface Processes and Landforms, 25(13), 1419-1428.

Gabet, E. J. (2003), Sediment transport by dry ravel, Journal of Geophysical Research, 108(B1), 2050, 2010.1029/2001JB001686.

Gabet, E. J. (2020), Lithological and structural controls on river profiles and networks in the northern Sierra Nevada, Geological Society of America Bulletin, 132(3-4), 655-667.

Gabet, E. J., O. J. Reichman, and E. Seabloom (2003), The effects of bioturbation on soil processes and sediment transport, Annual Review of Earth and Planetary Sciences, 31, 259-273.

Gabet, E. J., S. M. Mudd, D. T. Milodowski, K. Yoo, M. D. Hurst, and A. Dosseto (2015), Local topography and erosion rate control regolith thickness along a ridgeline in the Sierra Nevada, California, Earth Surface Processes and Landforms, 40(13), 17791790.

Gilbert, G. K. (1909), The convexity of hillslopes, Journal of Geology, 17, 344-350.

Granger, D. E., J. W. Kirchner, and R. C. Finkel (1996), Spatially averaged long-term erosion rates measured from in situ-produced cosmogenic nuclides in alluvial sediment, Journal of Geology, 104(3), 249-257.

Grieve, S. W. D., S. M. Mudd, and M. D. Hurst (2016), How long is a hillslope?, Earth Surface Processes and Landforms, 41(8), 1039-1054.

Hack, J. T. (1973), Stream-profile analysis and stream-gradient index, Journal of Research of the U.S. Geological Survey, 1(4), 421-429.

Hanks, T. C. (2000), The age of scarplike landforms from diffusion - equation analysis, Quaternary Geochronology: Methods and Applications, 313-338.

Hanks, T. C., and D. P. Schwartz (1987), Morphologic dating of the pre-1983 fault scarp on the Lost River Fault at Doublespring Pass Road, Custer County, Idaho, Bulletin of the Seismological Society of America, 77, 837-846.

Harel, M. A., S. M. Mudd, and M. Attal (2016), Global analysis of the stream power law parameters based on worldwide 10Be denudation rates, Geomorphology, 268, 184196.

Heidbach, O., M. Rajabi, K. Reiter, M. Ziegler, and W. Team (2016), World Stress Map Database Release 2016. V. 1.1, edited, GFZ Data Services.

Heimsath, A. M., D. J. Furbish, and W. E. Dietrich (2005), The illusion of diffusion: Field evidence for depth-dependent sediment transport, Geology, 33(12), 949-952.

Hurst, M. D., S. M. Mudd, R. C. Walcott, M. Attal, and K. Yoo (2012), Using hilltop curvature to derive the spatial distribution of erosion rates, Journal of Geophysical Research - Earth Surface, 115, 1-19.

Hurst, M. D., S. M. Mudd, K. Yoo, M. Attal, and R. C. Walcott (2013), Influence of lithology on hillslope morphology and response to tectonic forcing in the northern Sierra Nevada of California, Journal of Geophysical Research - Earth Surface, 118, 832-851.

Kirchner, P. B., R. C. Bales, N. P. Molotoch, J. Flanagan, and Q. Guo (2014), LiDAR measurement of seasonal snow accumulation along an elevation gradient in the southern Sierra Nevada, California, Hydrological Earth Systems Science, 18, 42614275 . 
Kohl, C. P., and K. Nishiizumi (1992), Chemical isolation of quartz for measurement of insitu -produced cosmogenic nuclides, Geochimica et Cosmochimica Acta, 56(9), 35833587.

Marshall, J. A., and L. S. Sklar (2012), Mining soil databases for landscape-scale patterns in the abundance and size distribution of hillslope rock fragments, Earth Surface Processes and Landforms, 37(3), 287-300.

Mifsud, C., T. Fujioka, and D. Fink (2013), Extraction and purification of quartz in rock using hot phosphoric acid for in situ cosmogenic exposure dating, Nuclear Instruments and Methods in Physics Research Section B: Beam Interactions with Materials and Atoms, 294, 203-207.

Miller, D. J., and T. Dunne (1996), Topographic perturbations of regional stresses and consequent bedrock fracturing, Journal of Geophysical Research, 101B, 25,523$525,536$.

Milodowski, D. T., S. M. Mudd, and E. T. Mitchard (2014), Erosion rates as a potential bottom-up control of forest structural characteristics in the Sierra Nevada Mountains, Ecology, 96(1), 31-38.

Milodowski, D. T., S. M. Mudd, and E. T. A. Mitchard (2015), Topographic roughness as a signature of the emergence of bedrock in eroding landscapes, Earth Surf. Dynam., 3(4), 483-499.

Mudd, S. M. (2017), Detection of transience in eroding landscapes, Earth Surface Processes and Landforms, 42(1), 24-41.

Mudd, S. M., and K. Yoo (2010), Reservoir theory for studying the geochemical evolution of soils, Journal of Geophysical Research: Earth Surface, 115(F03030).

Mudd, S. M., M. Harel, M. D. Hurst, S. W. D. Grieve, and S. M. Marrero (2016), The CAIRN method: Automated, reproducible calculation of catchment-averaged denudation rates from cosmogenic radionuclide concentrations, Earth Surface Dynamics, 4, 655-674.

Neely, A. B., R. A. DiBiase, L. B. Corbett, P. R. Bierman, and M. W. Caffee (2019), Bedrock fracture density controls on hillslope erodibility in steep, rocky landscapes with patchy soil cover, southern California, USA, Earth and Planetary Science Letters, 522, 186-197.

Nishiizumi, K., M. Imamura, M. W. Caffee, J. R. Southon, R. C. Finkel, and J. McAninch (2007), Absolute calibration of 10be AMS standards, Nuclear Instruments and Methods in Physics Research Section B: Beam Interactions with Materials and Atoms, 258(2), 403-413.

NOAA (2016), National Center for Environmental Information, edited.

Pelletier, J. D. (2017), Quantifying the controls on potential soil production rates: a case study of the San Gabriel Mountains, California, Earth Surf. Dynam., 5(3), 479-492.

Pelletier, J. D., et al. (2011), Calibration and testing of upland hillslope evolution models in a dated landscape: Banco Bonito, New Mexico, Journal of Geophysical Research: Earth Surface, 116(F4).

Perron, J. T., P. W. Richardson, K. L. Ferrier, and M. Lapotre (2012), The root of branching river networks, Nature, 492, 100-103.

PRISM (2014), PRISM Climate Group, edited. 
Rasmussen, C., and N. Tabor (2007), Applying a quantitative pedogenic energy model across a range of environmental gradients, Soil Science Society of America Journal, 71(6), 1719-1729.

Rempe, D. M., and W. E. Dietrich (2014), A bottom-up control on fresh-bedrock topography under landscapes, Proceedings of the National Academy of Sciences, 111(18), 65766581.

Richardson, P. W., J. T. Perron, and N. D. Schurr (2019), Influences of climate and life on hillslope sediment transport, Geology, 47, 423-426.

Riebe, C. S., J. W. Kirchner, D. E. Granger, and R. C. Finkel (2001), Minimal climatic control on erosion rates in the Sierra Nevada, California, Geology, 29(5), 447-450.

Riebe, C. S., L. S. Sklar, C. E. Lukens, and D. L. Shuster (2015), Climate and topography control the size and flux of sediment produced on steep mountain slopes, Proceedings of the National Academy of Sciences, 112(51), 15574-15579.

Roering, J. J., J. W. Kirchner, and W. E. Dietrich (1999), Evidence for non-linear, diffusive sediment transport on hillslopes and implications for landscape morphology, Water Resources Research, 35(3), 853-870.

Roering, J. J., J. W. Kirchner, and W. E. Dietrich (2001a), Hillslope evolution by nonlinear, slope-dependent transport: steady state morphology and equilibrium adjustment timescales, Journal of Geophysical Research, 106(B8), 16499-16513.

Roering, J. J., J. T. Perron, and J. W. Kirchner (2007), Functional relationships between denudation and hillslope form and relief, Earth and Planetary Science Letters, 264(1), 245-258.

Roering, J. J., J. W. Kirchner, L. S. Sklar, and W. E. Dietrich (2001b), Hillslope evolution by nonlinear creep and landsliding: An experimental study, Geology, 29(2), 143-146.

Roering, J. J., J. Marshall, A. M. Booth, M. Mort, and Q. Jin (2010), Evidence for biotic controls on topography and soil production, Earth and Planetary Science Letters, 298, 183-190.

Saucedo, G. J., and D. L. Wagner (1992), Geologic map of the Chico quadrangle, California, Division of Mines and Geology.

Slim, M., J. T. Perron, S. J. Martel, and K. Singha (2015), Topographic stress and rock fracture: a two-dimensional numerical model for arbitrary topography and preliminary comparison with borehole observations, Earth Surface Processes and Landforms, 40(4), 512-529.

Trabucco, A., and R. Zomer (2019), Global Aridity Index and Potential Evapotranspiration (ETO) Climate Database v2. CGIAR Consortium for Spatial Information

(CGIAR-CSI). Published online, available from the CGIAR-CSI GeoPortal at https://cgiarcsi.community.

Wakabayashi, J., and T. L. Sawyer (2000), Neotectonics of the Sierra Nevada and the Sierra Nevada-Basin and Range transition, California, with field trip stop descriptions for the northeastern Sierra Nevada, in Field Guide to the Geology and Tectonics of the Northern Sierra Nevada, edited by E. R. Brooks and L. T. Dida, pp. 173 - 212, California Division of Mines and Geology.

Wood, R. (2013), Transient hillslope response to an incision wave sweeping up a watershed: a case study from the Salmon River, MS thesis, 42 pp, San Jose State University, San Jose, CA. 
642 
643 Figure captions

644 Figure 1. Map of the United States showing the locations of the study sites.

645

646 Figure 2. Median hilltop curvature increases with the approximate square root of erosion

647 rate. Because ridgetops have negative curvature, the absolute value of curvature is plotted to

648 allow a power-law regression. For clarity, error bars are not shown here; uncertainties are

649 presented in Table 1.

650

651 Figure 3. Corrected median hilltop curvature vs. erosion rate. Accounting for grid-resolution

652 effects modifies the relationship between curvature and erosion rate, albeit only slightly

653 (compare with Figure 2).

654

655 Figure 4. Inferred transport efficiency $(D)$ increases approximately with the square root of

656 erosion rate. $D$ was calculated using the corrected hilltop curvatures.

658 Figure 5. Inferred transport efficiency $(D)$ vs. various climatic measures. Inferred transport

659 efficiency does not depend significantly on mean annual precipitation (A), mean annual

660 temperature (B), or the aridity index (C). Note that the plot for mean annual temperature does

661 not include the data set from Richardson et al. [2019], which did not provide these values.

662

663 Figure 6. Geometric mean of particle size $(R)$ increases with inferred erosion rate $(E)$ at the

664 Feather River site [Gabet et al., 2015]. Particle sizes of soil surface samples were measured

665 at regular intervals along a ridge with a gradient in erosion rates. Because local topography 
666 along the ridgeline (i.e., saddles and knobs) was found to have a strong control on soil

667 properties at this site, we present here only the data from the knobs. Erosion rate calculated

668 from ridgetop curvatures using the relationship reported in the present study. $1 \sigma$ for particle

669 size data averages $5.8 \mathrm{~mm}$ (error bars not shown for clarity).

670

671 Figure 7. Mean slope at the ridgeline increases with erosion rate. The steeper slopes

672 generally found in rapidly eroding landscapes can also be recognized along the ridgecrests.

674 Figure 8. Product of hilltop curvature and slope vs. erosion rate. The nearly linear

675 relationship between the two supports a sediment flux law of the form $q_{\mathrm{s}}=K S^{2}$. This linear

676 relationship may be a mathematical artefact.

677

678 Figure 9. Comparison of nonlinear sediment flux equations. Dashed line represents the

679 commonly used nonlinear equation calibrated with values determined in Roering et al.

680 [1999]. Solid line represents fluxes calculated with Eqn. (11b) and calibrated to provide a

681 comparison with the dashed line. Fluxes were calculated over the range of hilltop gradients

682 measured at our field sites. Note that a linear regression (not shown) through the dashed line

683 yields an $\mathrm{R}^{2}$ of 0.9999 , confirming the use of Eqn. (1) as an appropriate substitute for the

684 standard nonlinear equation at low slopes.

685

686 Figure 10. Curvature vs. erosion rate according to rock type. For the same erosion rate, the

687 hilltop curvature is lower at sites underlain with presumably weaker bedrock when compared

688 to sites with stronger bedrock. Sites shown with the square markers are Tennessee Valley 
689 (CA), Oregon Coast Range (OR), Gabilan Mesa (CA), and Allegheny Plateau (PA) [Perron

690 et al., 2012; Richardson et al., 2019].

691 


\begin{abstract}
Figure 1.
\end{abstract}

\begin{abstract}
$-1$
gure
\end{abstract}




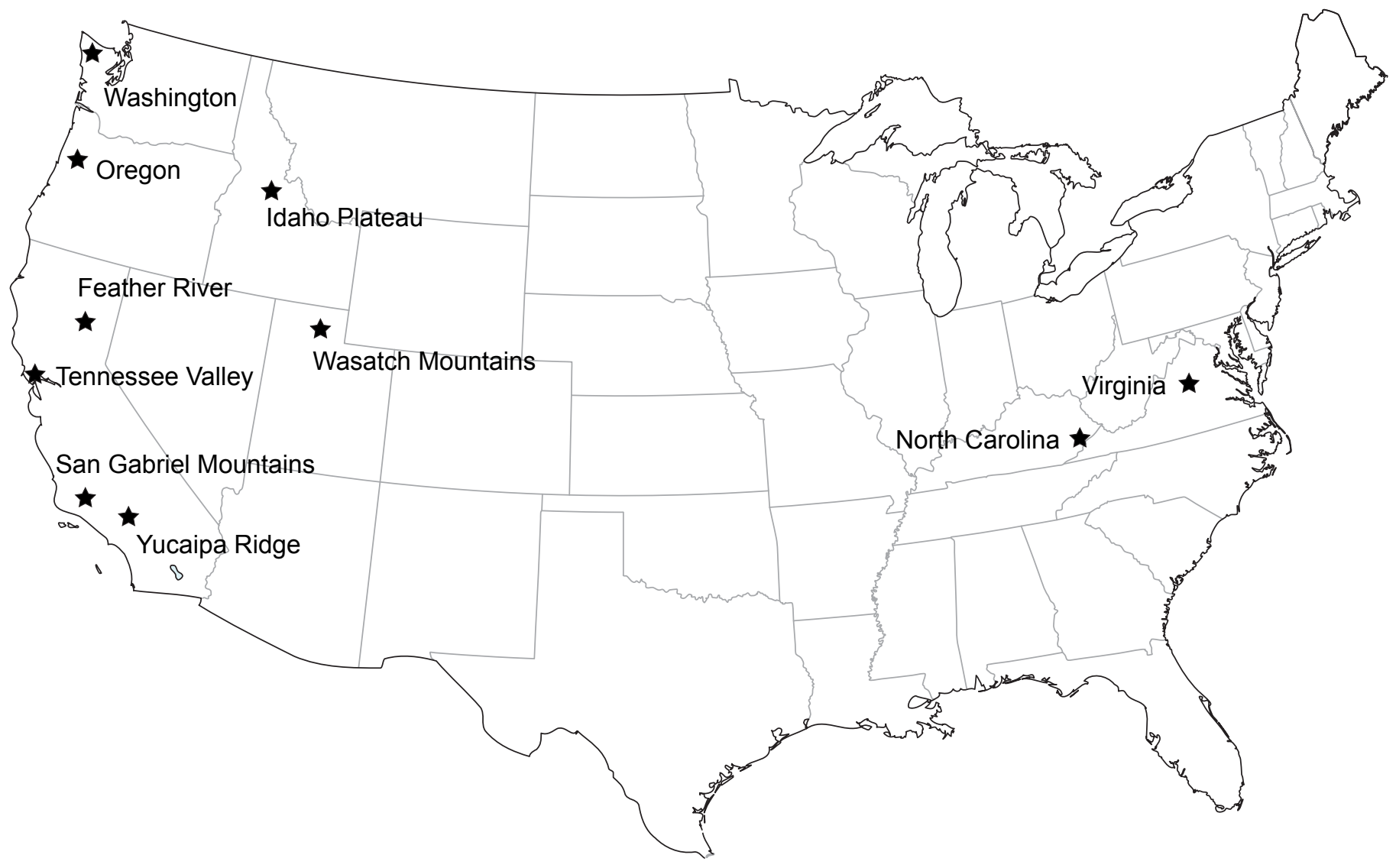




\begin{abstract}
Figure 2.
\end{abstract}




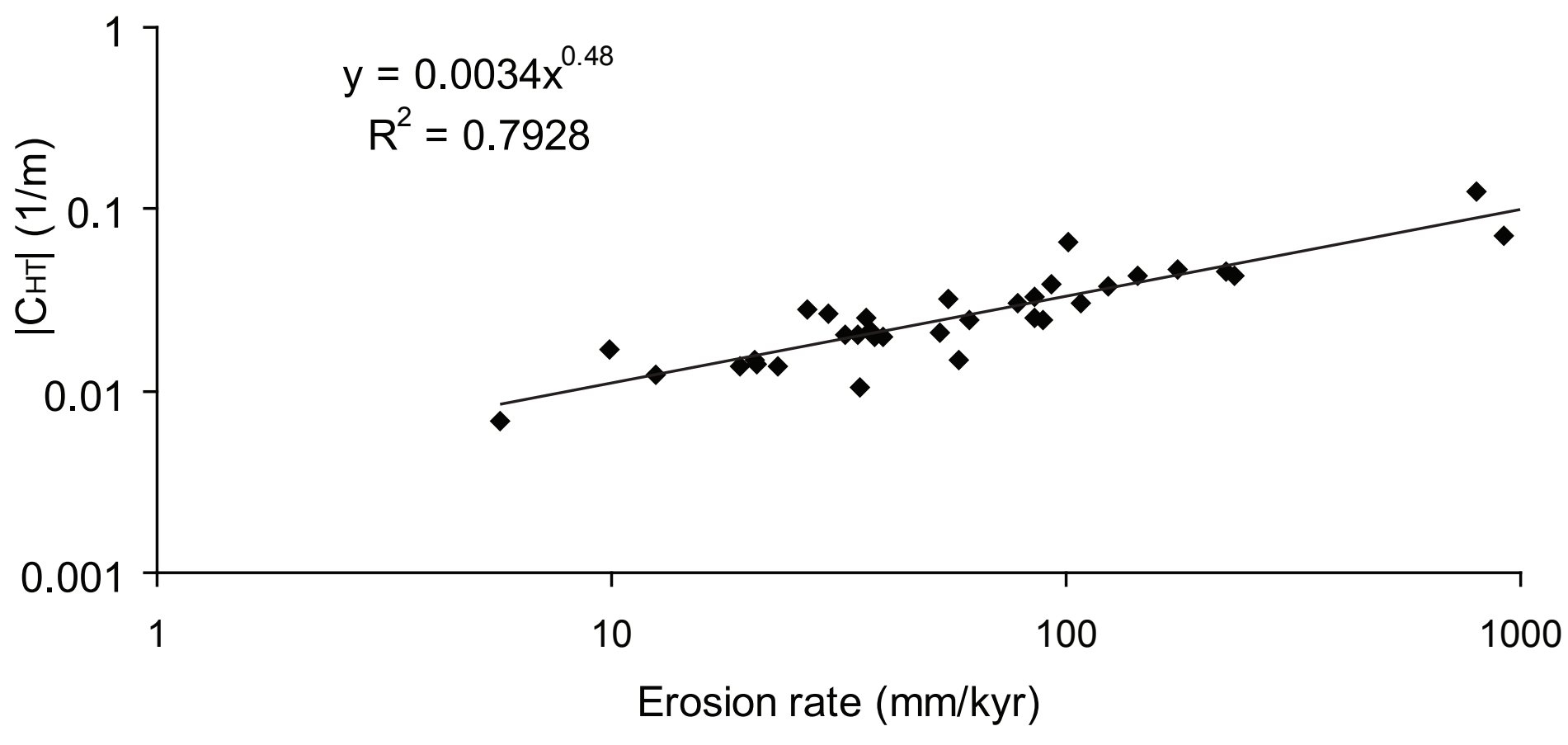




\begin{abstract}
Figure 3.
\end{abstract}
gure 3. 


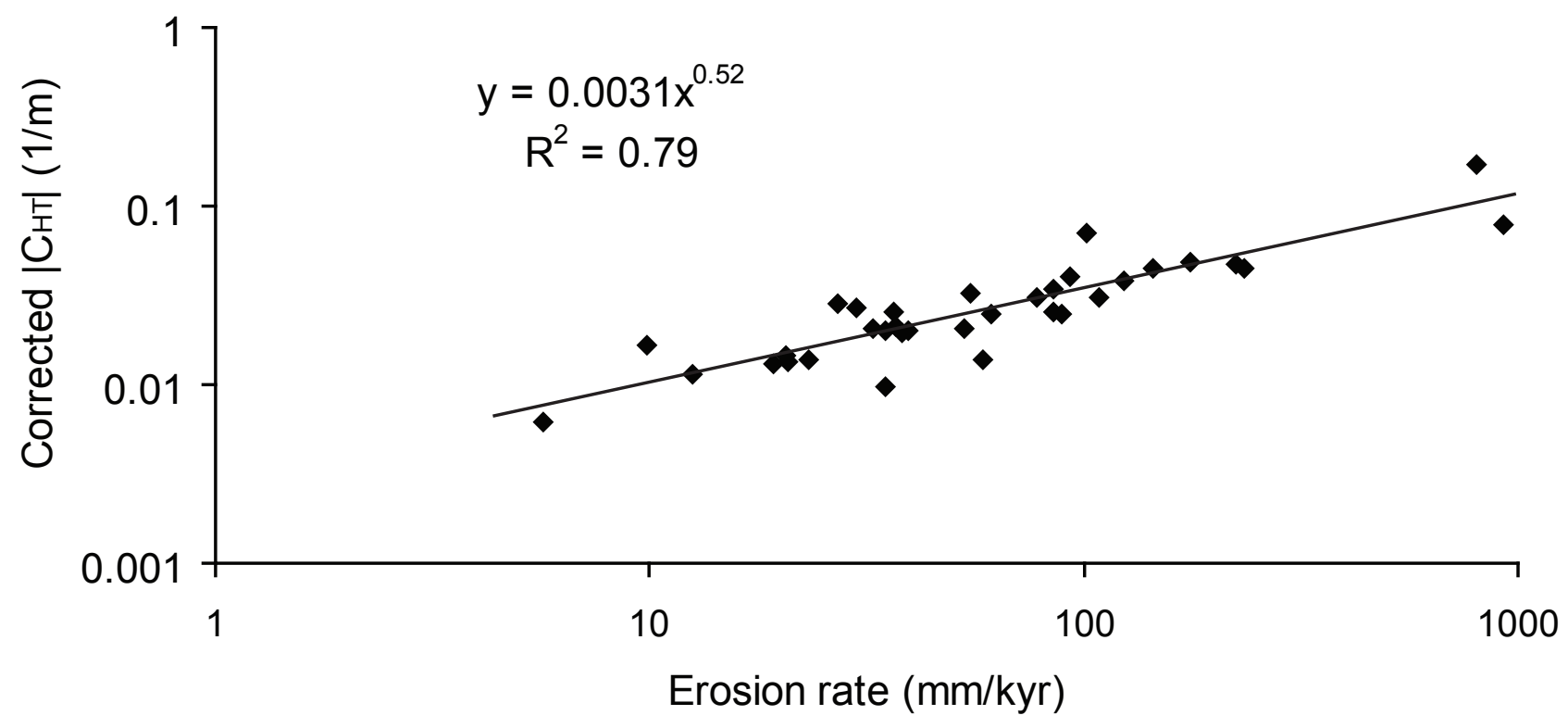


ESSOAr $\mid$ https://do
Figure 4.

gure 4.

Figure 4.

.
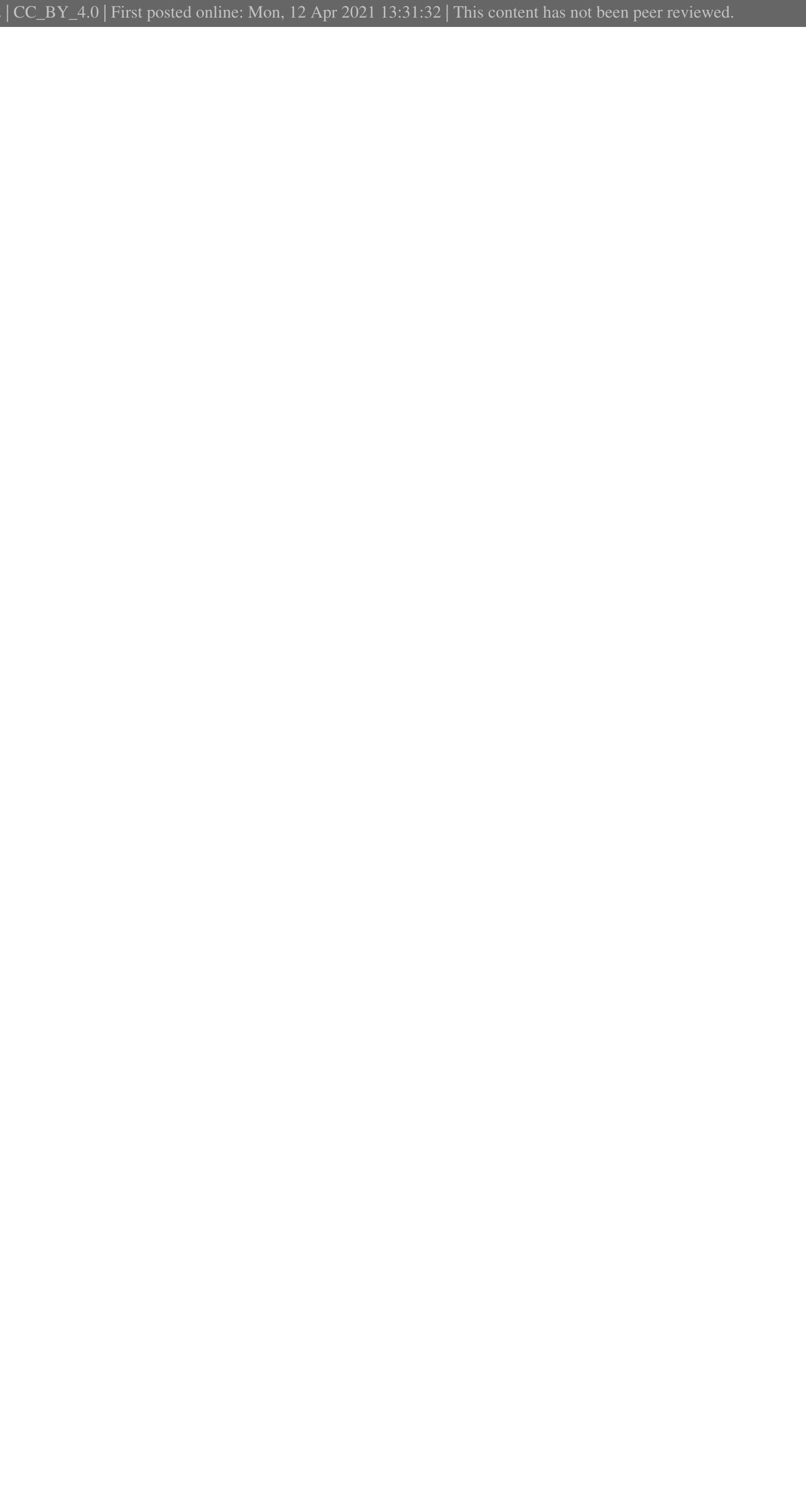


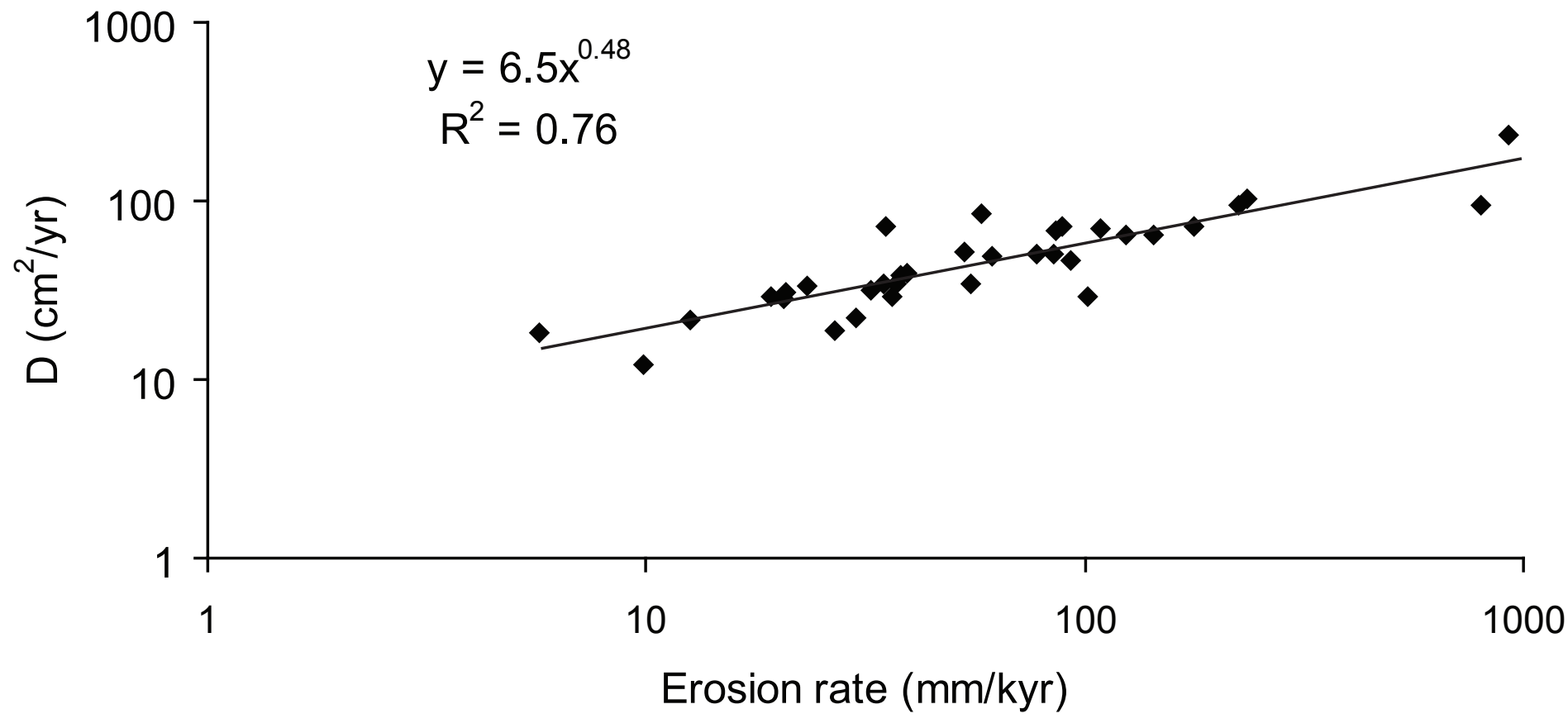




\begin{abstract}
Figure 5.
\end{abstract}
$-m$ 
(A)

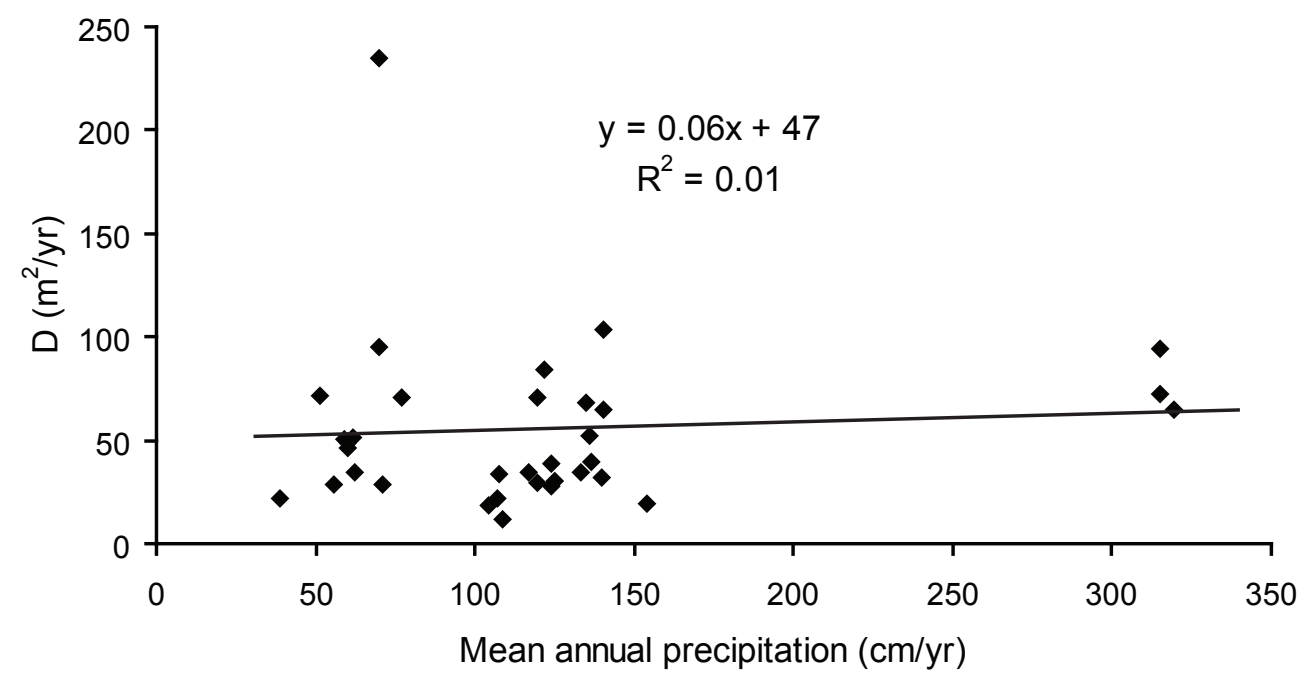

(B)

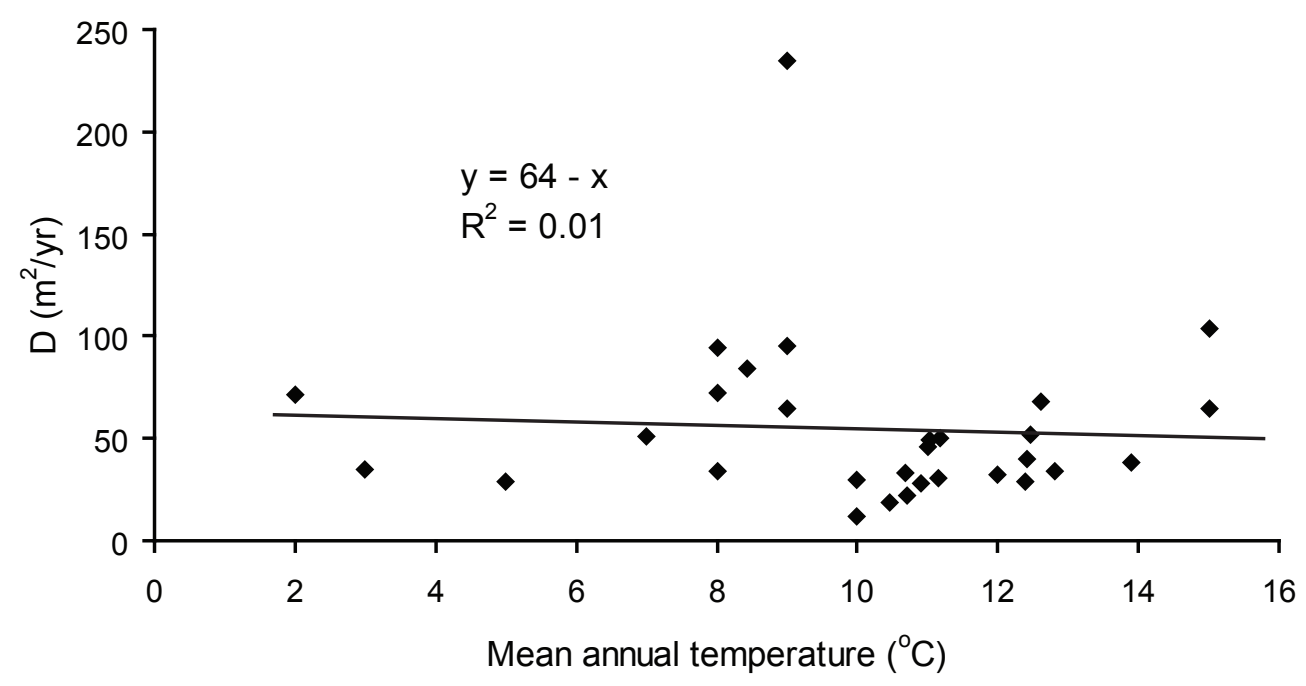

(C)

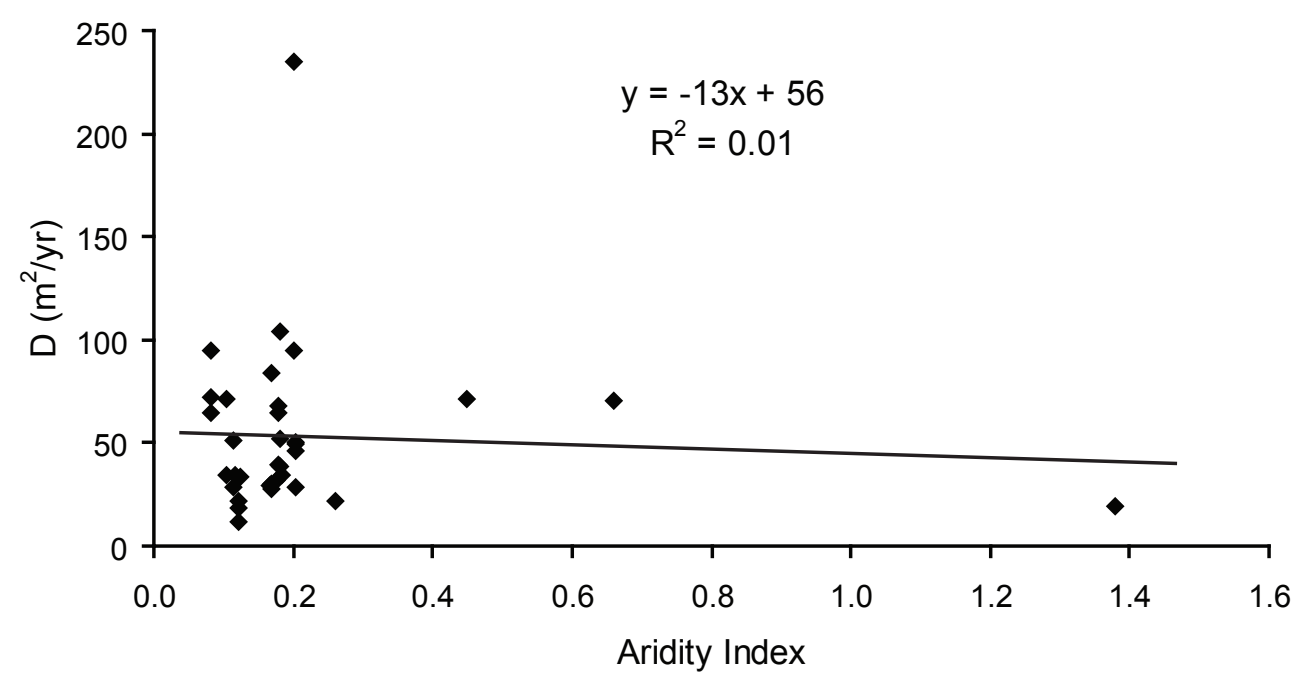


Figure 6.

figure 6.

ure 6. 


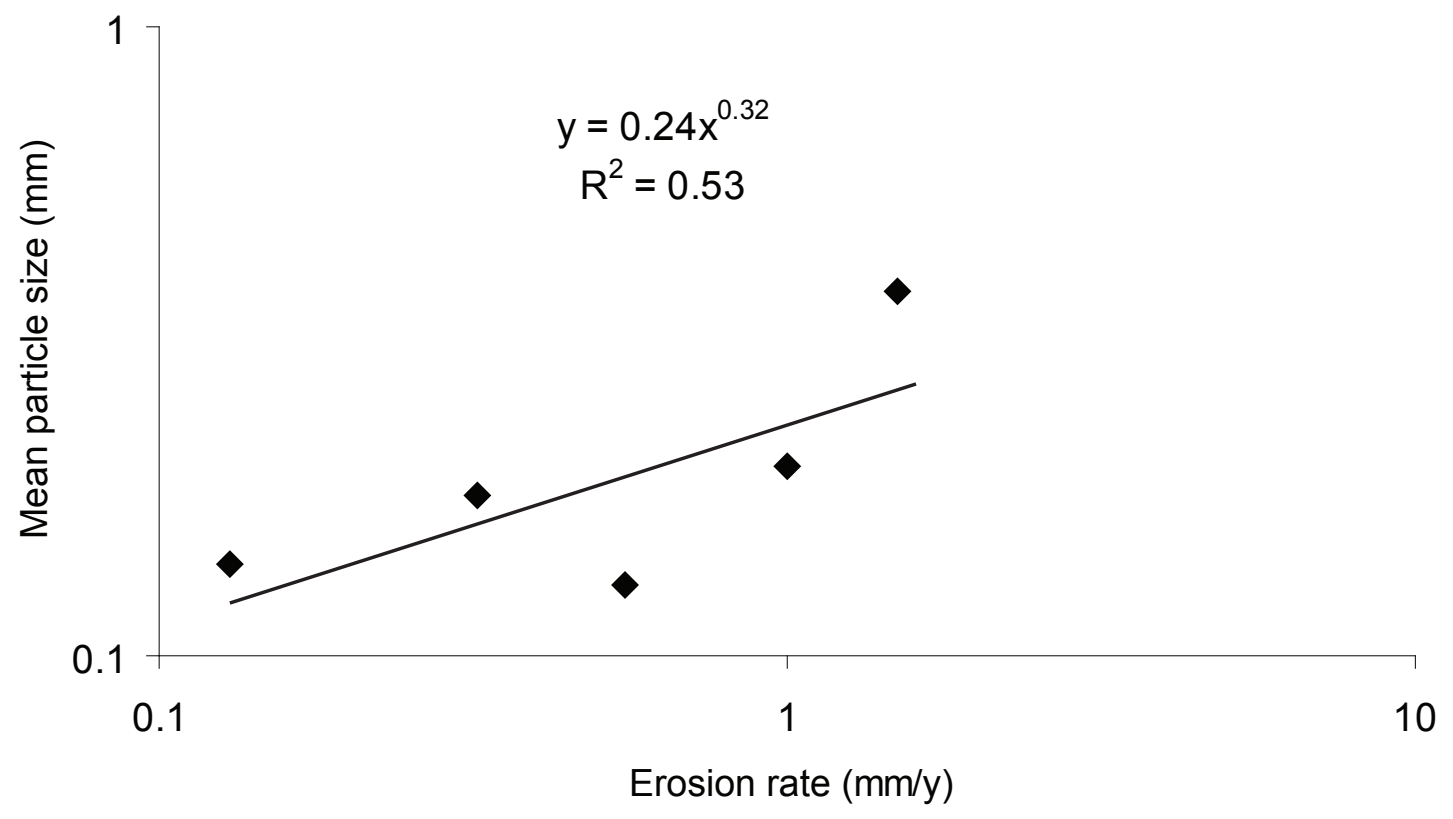


ESSOAr $\mid$ https://do

\begin{abstract}
Figure 7.
\end{abstract}




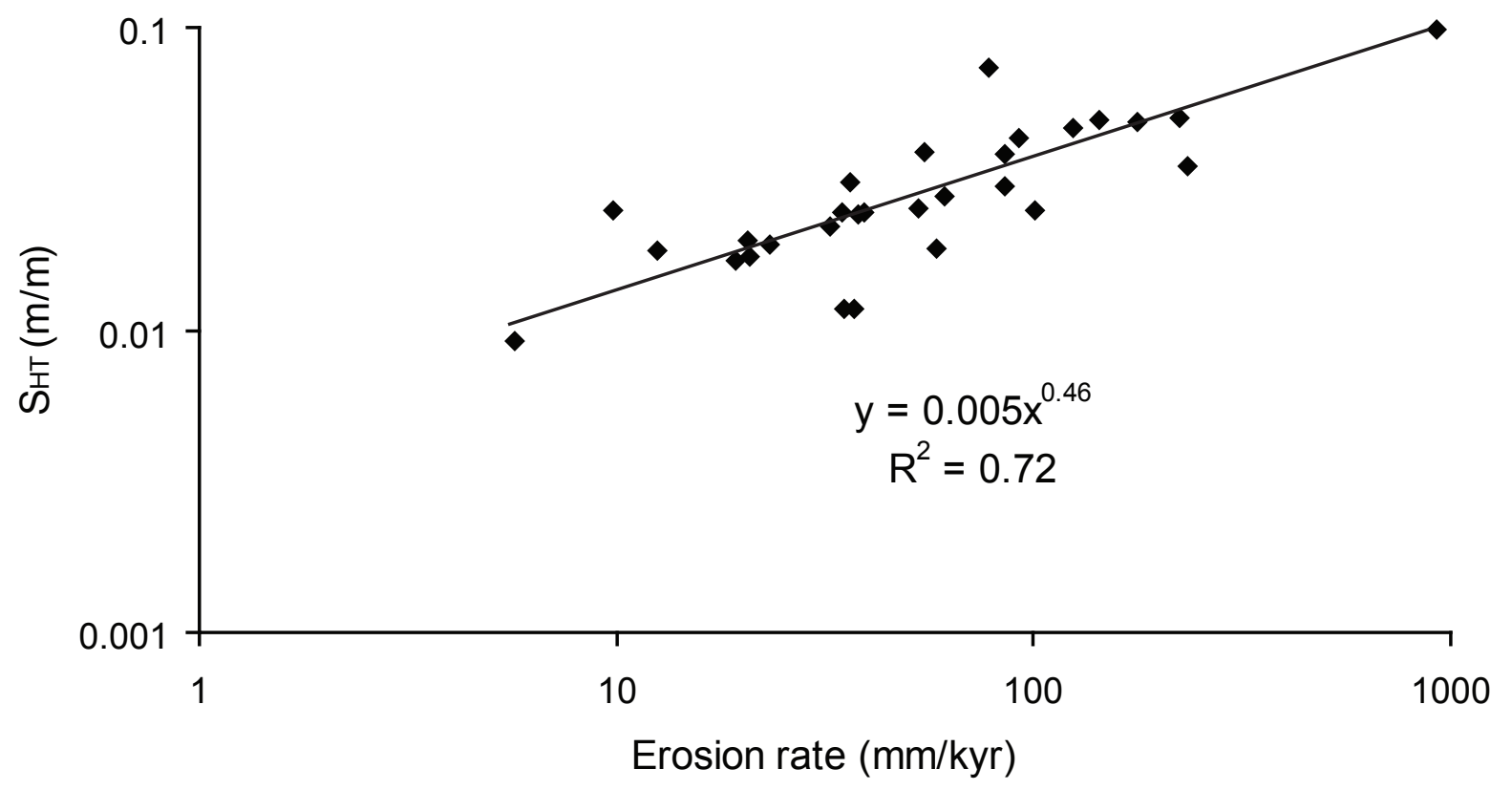


Figure 8. 


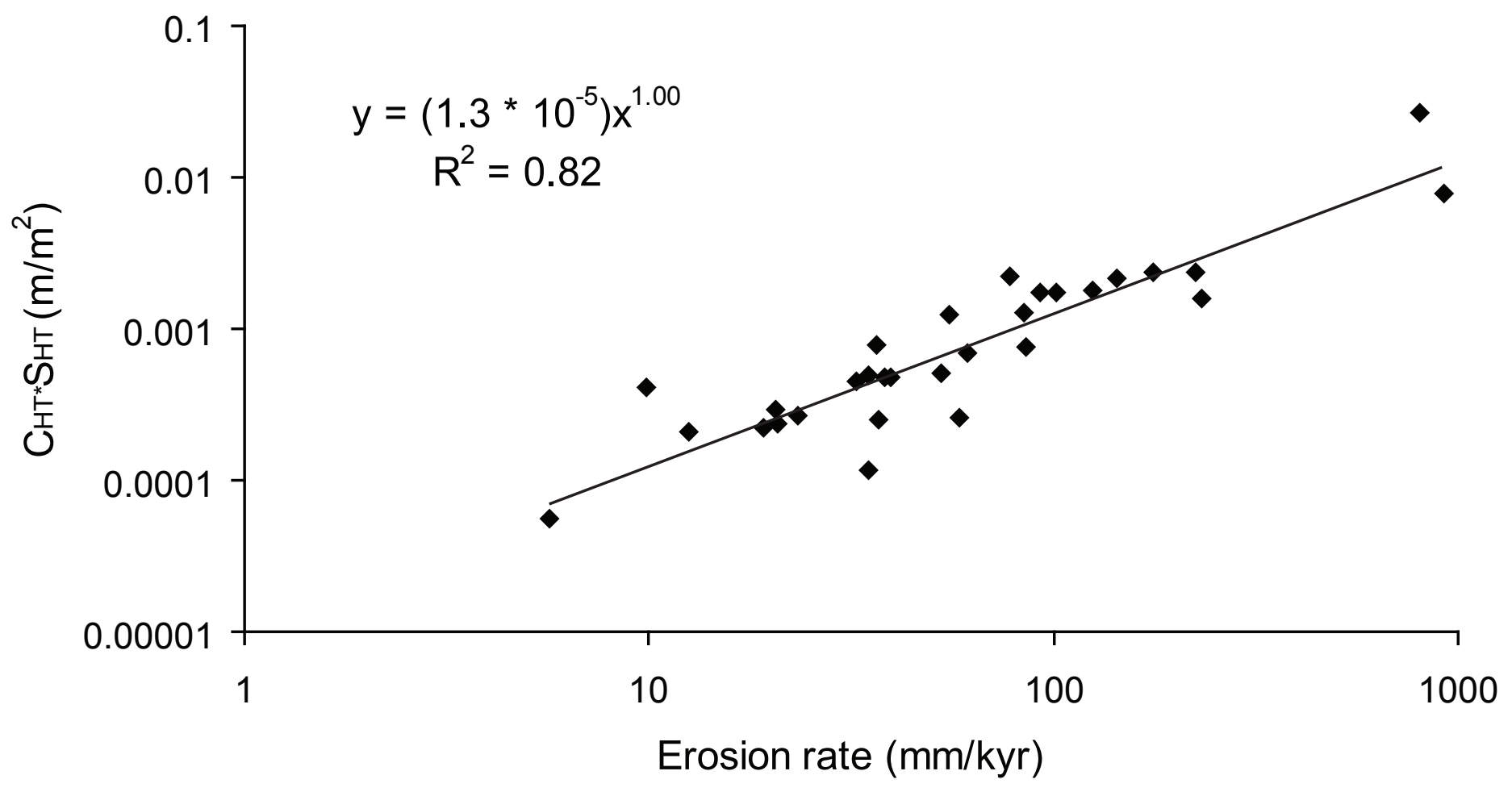


ESSOAr | https://doi.org/10.1002/
\[ \text { Figure 9. } \]

ESSOAr | https://doi.org/10.1002/
\[ \text { Figure 9. } \]

Figure 9.

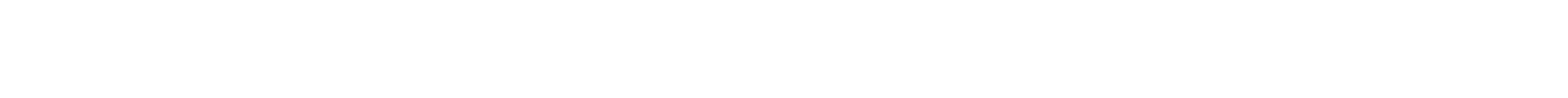

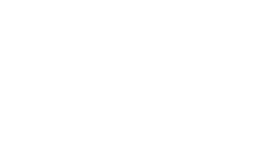

(1)

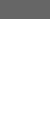

更

(1)

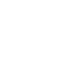




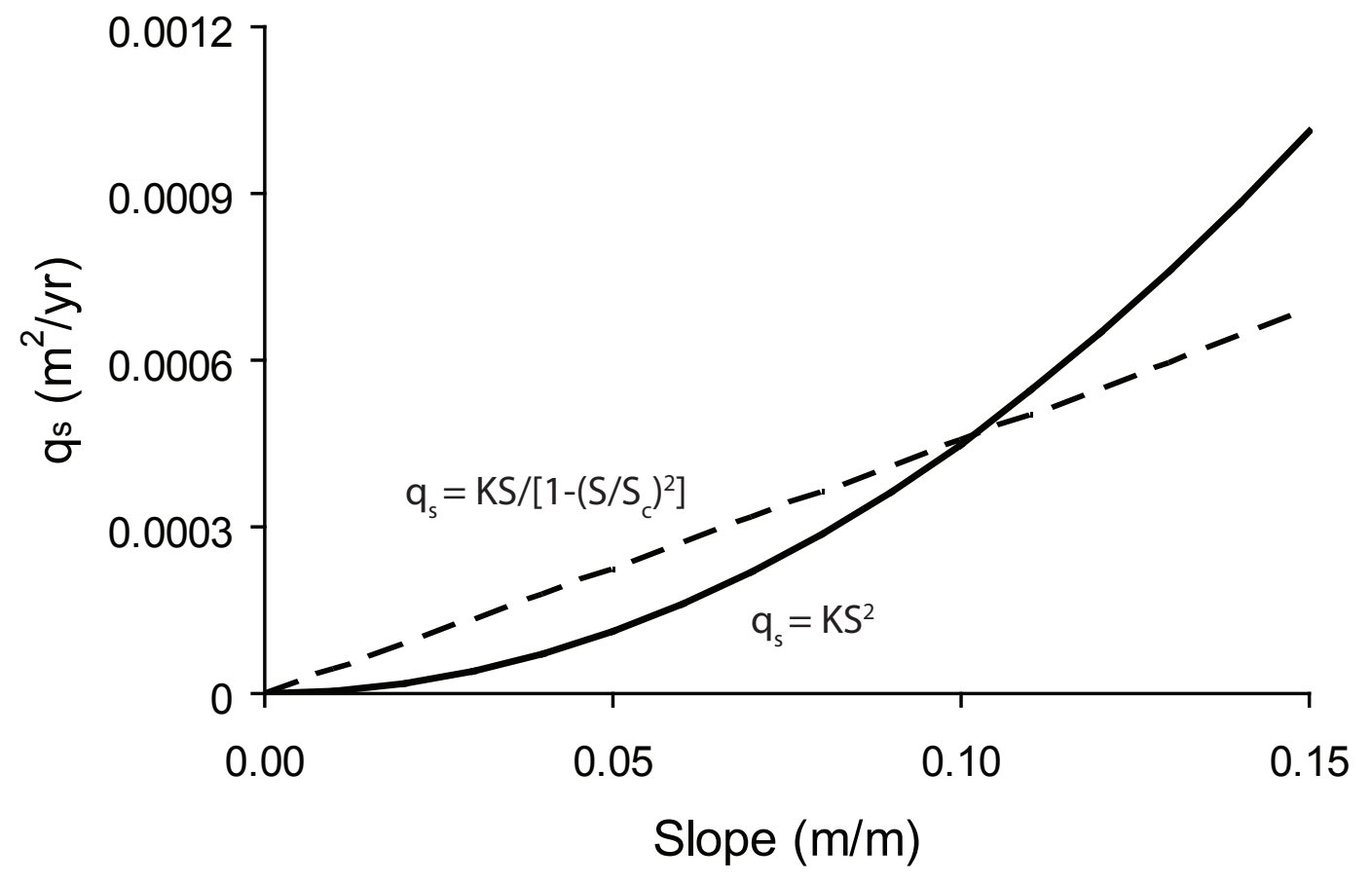


Figure 10.

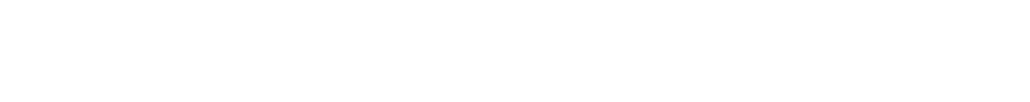

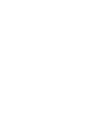

\footnotetext{
Figure 10.
} 


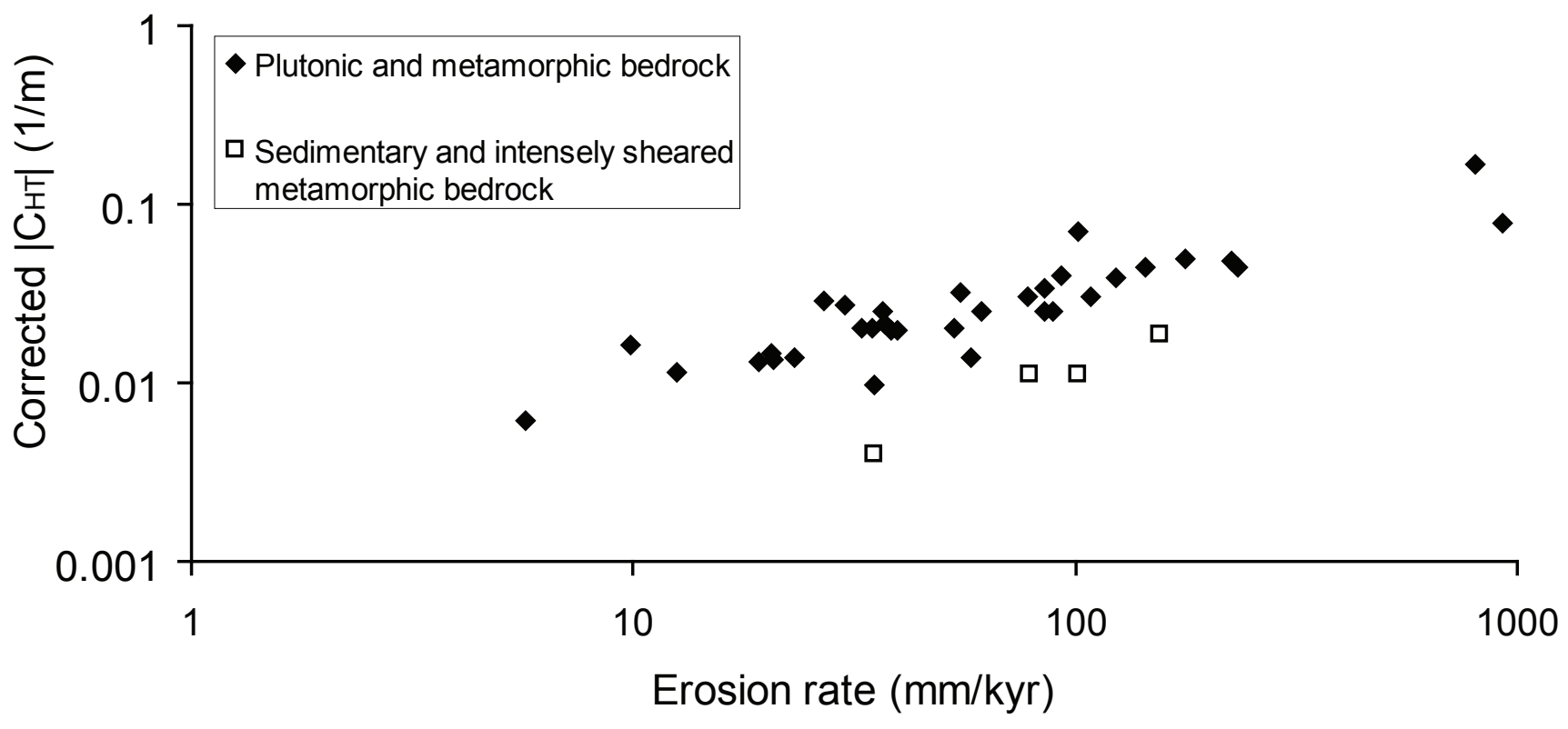


Table 1. Site information. (na = not available)

\begin{tabular}{|c|c|c|c|c|c|c|c|c|c|c|c|}
\hline Region & Source & $\begin{array}{l}\text { Sample } \\
\text { ID }\end{array}$ & $\begin{array}{l}\text { Latitude } \\
\qquad\left({ }^{\circ} \mathrm{N}\right)\end{array}$ & $\begin{array}{c}\text { Longitude } \\
\left({ }^{\circ} \mathrm{W}\right)\end{array}$ & $\begin{array}{l}\text { Lith- } \\
\text { ology }\end{array}$ & $\begin{array}{l}\mathrm{MAT}^{\mathrm{k}} \\
\left({ }^{\circ} \mathrm{C}\right)\end{array}$ & $\begin{array}{l}\text { MAP }^{k} \\
(\mathrm{~cm} / \mathrm{yr})\end{array}$ & $\begin{array}{l}\text { Eros. } \pm 1 \sigma \\
(\mathrm{mm} / \mathrm{kyr})\end{array}$ & $\begin{array}{l}\text { Med. Crv. } \\
(1 / \mathrm{m})\end{array}$ & $\begin{array}{c}\text { Ave. Slope } \\
(\mathrm{m} / \mathrm{m})\end{array}$ & $\begin{array}{c}D^{\prime} \pm 1 \sigma \\
\left(\mathrm{cm}^{2} / \mathrm{yr}\right)\end{array}$ \\
\hline San Gabriel & $a$ & SG128 & 34.3376 & 118.0104 & $\mathrm{gr}$ & 12 & 55.5 & $37 \pm 8$ & -0.02544 & 0.031 & $29 \pm 6$ \\
\hline Mountains & $\mathrm{a}$ & SG130 & 34.3783 & 117.9893 & $g r$ & 11 & 59.8 & $62 \pm 13$ & -0.02515 & 0.028 & $50 \pm 10$ \\
\hline \multirow[t]{3}{*}{ (CA) } & a & SG131 & 34.3666 & 117.9920 & $\mathrm{gr}$ & 11 & 58.8 & $85 \pm 20$ & -0.03410 & 0.038 & $49 \pm 12$ \\
\hline & a & SG132 & 34.3658 & 117.9891 & $\mathrm{gr}$ & 11 & 60.1 & $93 \pm 19$ & -0.04039 & 0.043 & $46 \pm 9$ \\
\hline & $b$ & na & 34.3640 & 117.9920 & $\mathrm{gr}$ & na & 77.1 & $108 \pm 17$ & -0.03086 & na & $70 \pm 12$ \\
\hline Idaho Plateau & c & S1 & 45.4773 & 114.9618 & tnlt & 8 & 62.4 & $55 \pm 11$ & -0.03254 & 0.039 & $34 \pm 7$ \\
\hline \multirow[t]{4}{*}{ (ID) } & c & $\mathrm{S} 2$ & 45.5008 & 114.9519 & tnlt & 5 & 71.0 & $101 \pm 21$ & -0.07189 & 0.025 & $28 \pm 7$ \\
\hline & c & S3 & 45.5262 & 114.9293 & tnlt & 3 & 116.6 & $37 \pm 7$ & -0.02139 & 0.012 & $34 \pm 7$ \\
\hline & c & $\mathrm{R} 2$ & 45.4843 & 114.9558 & tnlt & 7 & 61.8 & $78 \pm 16$ & -0.03083 & 0.073 & $51 \pm 11$ \\
\hline & $\mathrm{C}$ & R3 & 45.5348 & 114.9015 & tnlt & 2 & 119.8 & $35 \pm 7$ & -0.00971 & 0.019 & $72 \pm 14$ \\
\hline \multirow[t]{2}{*}{$\begin{array}{l}\text { Yucaipa Ridge } \\
\text { (CA) }\end{array}$} & $d$ & 3 & 34.0497 & 116.9280 & $\begin{array}{l}\text { qm, } \\
\text { gns }\end{array}$ & 9 & 70.1 & $922 \pm 203$ & -0.08083 & 0.092 & $\begin{array}{c}228 \pm \\
57\end{array}$ \\
\hline & $d$ & 4 & 34.0530 & 116.9401 & $\begin{array}{l}\text { qm, } \\
\text { gns }\end{array}$ & 9 & 70.1 & $801 \pm 175$ & -0.18688 & 0.159 & $86 \pm 28$ \\
\hline Blasingame (CA) & $b$ & na & 36.9540 & 119.6310 & tnlt & na & 38.7 & $30 \pm 4$ & -0.02727 & na & $22 \pm 3$ \\
\hline Olympic & $\mathrm{e}$ & U-WC-S & 47.7399 & 124.0457 & gw & 8 & 315.1 & $177 \pm 39$ & -0.04884 & 0.049 & $72 \pm 17$ \\
\hline \multirow[t]{2}{*}{ Peninsula (WA) } & e & L-WC-S & 47.7302 & 124.0379 & gw & 8 & 315.1 & $225 \pm 51$ & -0.04755 & 0.050 & $95 \pm 22$ \\
\hline & $\mathrm{e}$ & L-EFMC-S & 47.6581 & 124.2432 & gw & 9 & 319.6 & $144 \pm 34$ & -0.04422 & 0.049 & $65 \pm 16$ \\
\hline Blue Ridge & $f$ & SH-01a & 38.5713 & 78.2873 & $g r$ & 11 & 107.5 & $23 \pm 5$ & -0.01391 & 0.019 & $33 \pm 7$ \\
\hline Mountains & $f$ & $\mathrm{SH}-02 \mathrm{a}$ & 38.6636 & 78.3550 & $\mathrm{mb}$ & 10 & 104.5 & $6 \pm 1$ & -0.00616 & 0.009 & $19 \pm 4$ \\
\hline \multirow[t]{2}{*}{ (VA) } & $f$ & $\mathrm{SH}-07$ & 38.5816 & 78.4144 & $\mathrm{gr}$ & 10 & 108.6 & $10 \pm 2$ & -0.01699 & 0.025 & $12 \pm 2$ \\
\hline & $f$ & $\mathrm{SH}-10$ & 38.6572 & 78.2822 & $\mathrm{gr}$ & 11 & 106.8 & $13 \pm 3$ & -0.01203 & 0.018 & $21 \pm 5$ \\
\hline Feather River & $\mathrm{g}$ & BRB-2 & 39.6491 & 121.3020 & qd & 12 & 140.0 & $33 \pm 7$ & -0.02036 & 0.022 & $32 \pm 7$ \\
\hline \multirow[t]{7}{*}{$(\mathrm{CA})$} & $\mathrm{h}$ & BEAN-1 & 39.6126 & 121.3295 & $q d$ & 13 & 133.2 & $35 \pm 8$ & -0.02013 & 0.024 & $35 \pm 7$ \\
\hline & $\mathrm{h}$ & BEAN-2 & 39.6225 & 121.3283 & $q d$ & 14 & 124.0 & $38 \pm 8$ & -0.01969 & 0.024 & $39 \pm 8$ \\
\hline & $\mathrm{h}$ & BEAN-4 & 39.6237 & 121.3273 & $q d$ & 12 & 136.1 & $53 \pm 12$ & -0.02097 & 0.025 & $51 \pm 11$ \\
\hline & $\mathrm{h}$ & BEAN-5 & 39.6312 & 121.3298 & qd & 13 & 136.5 & $40 \pm 8$ & -0.01954 & 0.024 & $40 \pm 8$ \\
\hline & i & BEAN-7 & 39.6284 & 121.3277 & $q d$ & 13 & 134.7 & $85 \pm 18$ & -0.02557 & 0.030 & $67 \pm 14$ \\
\hline & $\mathrm{i}$ & FT-3 & 39.6714 & 121.3109 & qd & 11 & 123.7 & $21 \pm 4$ & -0.01425 & 0.017 & $29 \pm 6$ \\
\hline & $\mathrm{i}$ & FT-4 & 39.6712 & 121.3109 & $q d$ & 11 & 124.8 & $21 \pm 4$ & -0.01513 & 0.020 & $27 \pm 6$ \\
\hline
\end{tabular}




\begin{tabular}{|c|c|c|c|c|c|c|c|c|c|c|c|}
\hline & i & FT-6 & 39.6784 & 121.3155 & qd & 10 & 119.8 & $19 \pm 4$ & -0.01338 & 0.017 & $29 \pm 6$ \\
\hline & i & SB-1 & 39.7189 & 121.2411 & qd & 8 & 121.9 & $58 \pm 12$ & -0.01475 & 0.019 & $79 \pm 17$ \\
\hline & $\mathrm{i}$ & FR-4 & 39.6344 & 121.2771 & qd & 15 & 140.5 & $234 \pm 79$ & -0.04535 & 0.035 & $\begin{array}{c}103 \pm \\
36\end{array}$ \\
\hline & $\mathrm{i}$ & FR-5 & 39.6354 & 121.2713 & qd & 15 & 140.5 & $124 \pm 39$ & -0.03858 & 0.047 & $64 \pm 21$ \\
\hline $\begin{array}{l}\text { Wasatch Mtns } \\
\text { (Utah) }\end{array}$ & $b$ & na & 40.8920 & 111.8650 & $g r$ & na & 51.5 & $89 \pm 9$ & -0.02507 & na & $71 \pm 15$ \\
\hline $\begin{array}{l}\text { Great Smokey } \\
\text { Mtns (NC) }\end{array}$ & $b$ & na & 35.6220 & 83.2040 & qtz & na & 154.0 & $27 \pm 2$ & -0.02872 & na & $19 \pm 1$ \\
\hline
\end{tabular}

${ }^{a}$ Source for ${ }^{10}$ Be data and lithology: [DiBiase et al., 2010]

b Source for all data: [Richardson et al., 2019]

c Samples were collected for this study; source for lithology: [Wood, 2013]

${ }^{d}$ Source for ${ }^{10}$ Be data and lithology: [Binnie et al., 2007]

e Source for ${ }^{10} \mathrm{Be}$ data and lithology: [Belmont et al., 2007]

${ }^{f}$ Source for ${ }^{10}$ Be data and lithology: [Duxbury, 2009]

g Source for ${ }^{10}$ Be data for all Feather River samples except FR-4 and FR-5: [Hurst et al., 2012]

h Source for ${ }^{10}$ Be data for FR-4 and FR-5: [Riebe et al., 2001]

Source for lithology: [Saucedo and Wagner, 1992]

$\mathrm{j}$ gr = granitic, tnlt = tonalite, $\mathrm{qm}=$ quartz monzonite, gns = gneiss, gw = greywacke, $\mathrm{mb}=$ metabasalt, qd = quartz diorite, qtz = quartzite

$k$ applies to data from all sources except Richardson et al [2019]; MAT = mean annual temperature; MAP = mean annual precipitation; data from the PRISM Climate Group, http://prism.oregonstate.edu, accessed 25 March 2017

${ }^{\prime}$ Values corrected for grid-resolution effects. Grid-resolution adjustment for sites L-WC-S, L-EFMC-S, SH-01a, SH-02a used a 12-m analysis window because adustments using 14-window failed to converge to a solution. Sensitivity analyses indicate an average difference of $<2 \%$ for curvature corrections using a window diameter of $12 \mathrm{~m}$ vs. $14 \mathrm{~m}$. 
Table 2. Details of ${ }^{10} \mathrm{Be}$ analysis from Idaho site.

\begin{tabular}{|l|l|l|l|l|}
\hline Sample ID & $\begin{array}{l}\text { Sample } \\
\text { depth } \\
\text { intervals } \\
(\mathrm{cm})\end{array}$ & $\begin{array}{l}\text { AMS } \\
\text { measurement } \\
\text { ID }\end{array}$ & $\begin{array}{l}{ }^{10} \mathrm{Be} \\
\text { concentration } \\
\left(\mathrm{x} 10^{3} \text { at }^{-1}\right)\end{array}$ & $\begin{array}{l}{ }^{10} \mathrm{Be} \\
\text { concentration } \\
\text { uncertainty } 1 \sigma \\
\left({\mathrm{x} 10^{3}} \text { at g }^{-1}\right)\end{array}$ \\
\hline S1 & $0-2$ & $\mathrm{~s} 04446$ & 119.9 & 5.7 \\
\hline S2 & $8-10$ & $\mathrm{~s} 04447$ & 91.94 & 7.18 \\
\hline S3 & $16-18$ & $\mathrm{~s} 04448$ & 373.7 & 17.8 \\
\hline R2 & $\mathrm{n} / \mathrm{a}$ & $\mathrm{s} 04450$ & 91.49 & 4.43 \\
\hline R3 & $\mathrm{n} / \mathrm{a}$ & $\mathrm{s} 04451$ & 408.8 & 15.1 \\
\hline R4 & $\mathrm{n} / \mathrm{a}$ & $\mathrm{s} 04452$ & 480.1 & 16.6 \\
\hline
\end{tabular}

